\title{
Functionalized Nanosilica for Vulcanization Efficiency and Mechanical Properties of Natural Rubber Composites
}

Dileep Padmanabhan ( $\sim$ pdileep84@gmail.com )

Rubber Park India (P) Ltd. https://orcid.org/0000-0002-8570-6672

Sinto Jacob

St.Aloysius College

C.S. Julie Chandra

Maharaja's College Ernakulam

Midhun Dominic C.D

Sacred Heart College Thevara

\section{Poornima M P}

Sree Sankara Vidyapeetom College

Sunil K. Narayanankutty

Cochin University of Science and Technology

\section{Research Article}

Keywords: Nanosilica, Surface modification, Sodium isopropyl xanthate, Thermal conductivity: Flex crack resistance

Posted Date: April 26th, 2021

DOl: https://doi.org/10.21203/rs.3.rs-375888/v1

License: (9) This work is licensed under a Creative Commons Attribution 4.0 International License. Read Full License

Version of Record: A version of this preprint was published at Silicon on August 6th, 2021. See the published version at https://doi.org/10.1007/s12633-021-01281-3. 
March 29, 2021

From

Dr. P. Dileep

Assistant Director,

J J Murphy Research Centre, Rubber Park India Pvt.Ltd., Airapuram,

Kerala, India

Ph: +9447821677

E-mail: pdileep84@gmail.com,dr@rubberparkindia.org

To

Executive Editor

silicon

Dear Editor,

Kindly see the manuscript entitled " Functionalized nanosilica for vulcanization efficiency and mechanical properties of natural rubber composites", for your kind consideration to publish in the Journal of "silicon". This has not been published elsewhere nor has it been submitted simultaneously for publication elsewhere.

Thank you very much for your consideration.

Yours Sincerely, Dr. P. Dileep 


\section{Functionalized nanosilica for vulcanization efficiency and mechanical properties of natural rubber composites}

P. Dileep*a,b ${ }^{*}$ Sinto Jacob ${ }^{\text {c }}$, C.S. Julie Chandra ${ }^{\text {d }}$, Midhun Dominic C.D ${ }^{\text {e }}$, Poornima M P ${ }^{\text {f }}$, Sunil K. Narayanankutty ${ }^{\text {a }}$

${ }^{a}$ Department of Polymer Science and Rubber Technology, Cochin University of Science and Technology (CUSAT), Cochin-682022, India.

b J J Murphy Research Centre, Rubber Park India Pvt. Ltd., Airapuram, Kerala, Pin-683556, India

${ }^{c}$ Department of Chemistry, St. Aloysius College, Elthuruth,Thrissur, Kerala, Pin-680611, India

${ }^{d}$ Department of Chemistry, Maharaja's College, Ernakulam, Kerala, Pin-682011, India

${ }^{\text {e }}$ Department of Chemistry, Sacred Heart College, Thevara, Kochi, Kerala, Pin-682013, India

${ }^{\mathrm{f}}$ Department of Chemistry, Sree Sankara Vidyapeetom College, Valayanchirangara, Kochi, Kerala, Pin-683556, India

*Corresponding author. Tel.: 9447821677

E-mail address: pdileep84@gmail.com, dr@ rubberparkindia.org

\section{Graphical abstract}

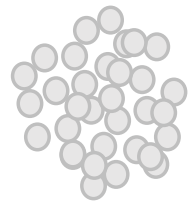

Nano silica

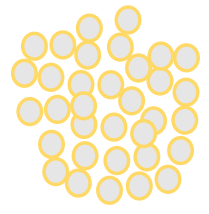

Modified nano silica

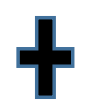

Sodium isopropyl xanthate
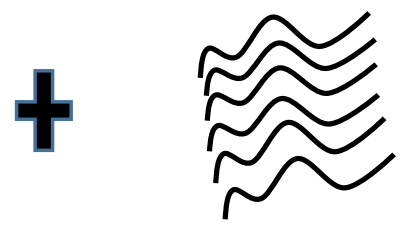

NR chains
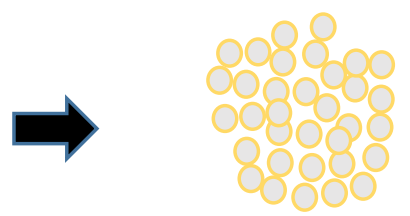

Modified nano silica

Vulcanization

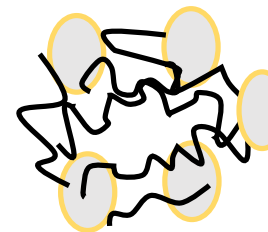

More chain entanglements between NR chains and modified nanosilica 


\title{
Highlights
}

- Sodium isopropyl xanthate (SIPX) is an efficient accelerator for silica modification.

- SIPX- bound nanosilica improves cure time of natural rubber (NR) compounds.

- Improved silica - rubber interaction is achieved by SIPX modification.

- Thermal aging properties of NR composites are improved by SIPX-NS addition.

\begin{abstract}
Accelerator functional character was introduced on nanosilica by the chemical reaction of sodium isopropyl xanthate (SIPX) with nanosilica (NS). Functional characteristics of nanosilica were confirmed by the Elemental analysis, thermogravimetric analysis, and infrared spectroscopy. This SIPX functionalized nanosilica (SIPX-NS) incorporated natural rubber (NR) compounds were used to evaluate the dispersion of silica in rubber and also the interaction between rubber and filler. The finely dispersed SIPX-NS particles in the NR matrix are revealed from the morphological analysis. Subtle changes in surface chemistry of silica had a profound influence on the dispersibility in NR matrix. NR 4SIPX-NS composite exhibited improved cure time, tensile strength, flex crack resistance and aging resistance relative to those of NR NS composite. This simple, efficient and cost-effective surface modification of silica improved the vulcanization efficiency and mechanical performance of NR composites and has great potential in the fabrication of high-performance polymer composites.
\end{abstract}

Keywords: Nanosilica; Surface modification; Sodium isopropyl xanthate; Thermal conductivity: Flex crack resistance

\section{Introduction}

Nanosilica is an emerging environment-friendly nanofiller used for the reinforcement of elastomers and is not derived from petroleum resources [1][2]. These nanoparticles have high surface energy and a tendency to agglomerate because of the groups like siloxane and silanol 
present on silica surface [3]. To overcome this disadvantage, modification of the surface chemistry is necessary to improve its dispersion and compatibility in an organic matrix.

The surface modification of silica particles can be achieved by different chemical procedures such as organoalkoxysilane modification [4][5], polymer grafting [6][7], encapsulation [8][9], etc. The modification on the surface of silica through reactions with organosilanes is used in the polymer and rubber industry for the improvement in mechanical properties. The interface between the polymer and filler surface affects the nonlinear viscoelastic behavior, improves mechanical properties and energy efficiency of rubber nanocomposites [10]. Chen et al. [11] proposed another method for surface modification of nanofillers with supported rubber additives. Silica-supported vulcanizing accelerator was prepared by grafting 2-benzothiazolethiol [12] onto the surface of silane modified silica to improve the silica-matrix interaction and silica dispersion in SBR. Mathew et al. [13] found that plasma treatment of silica could improve the interfacial interaction and mechanical properties of SBR composites. Wang et al. [14] developed surface modified silica nanoparticles by combining noncovalent and covalent modification processes in a simple, efficient and costeffective method. Weng et al. [15] developed a new way to promote the dispersion of silica and interfacial strength in rubber/silica composites by grafting with oniums. Liu et al. [16] established a simple inhibition-grafting method to prepare silica/polydimethylsiloxane nanocomposites with superior mechanical properties and a low viscosity. Guo et al. [17] used sorbic acid to improve the dispersion of silica and mechanical performance of SBR/silica composites.

Natural rubber, an unsaturated elastomer has been widely used due to its excellent elastic property. However, a few drawbacks such as low polarity, poor oil resistance and low air impermeability limit its application in some cases [18]. To overcome these drawbacks, NR is modified appropriately. Xu et al. [19] used Epoxidised Natural Rubber (ENR) as an interfacial 
modifier to improve the mechanical and dynamical mechanical properties of $\mathrm{NR} /$ silica composites. The results indicated the formation of a covalent bond by the ring-opening reaction between the epoxy groups of ENR chains and Si-OH groups on the silica surfaces. Ismail et al. [20] selected maleated natural rubber as a coupling agent for paper sludge fiber filled NR composites and found excellent rheological and dynamic properties. According to Gelling [21], NR backbone stereo-regularity disrupted by any type of chemical modifications and hence, reduction in basic strength properties of NR.

In the present work, instead of using the conventional coupling agents, a solid, watersoluble accelerator sodium isopropyl xanthate (SIPX) was adopted as a novel modifier for silica to improve its dispersion in NR matrix and for better interfacial interaction between the matrix and the filler. The modification and its size distribution were characterized by FTIR, TGA, EDX, SEM and dynamic light scattering (DLS). Modification of nanosilica improved curing, mechanical performance, crosslink density and aging resistance of NR.

\section{Experimental}

\subsection{Materials}

Rubber Research Institute of India (RRII), Kottayam provided ISNR-5 grade Natural

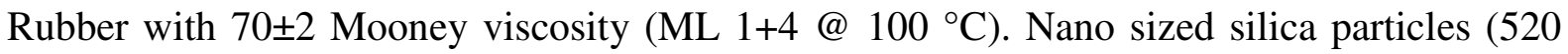

$\mathrm{m}^{2} / \mathrm{g}$. surface area) synthesized in our laboratory [22]. Sodium Isopropyl Xanthate (SIPX) was purchased from Amruta Industries, Mumbai, India. Commercial grades of Tetramethylthiuram disulphide (TMTD), stearic acid, sulphur (S), N-cyclohexyl-2-benzothiazole sulphenamide (CBS), and Zinc oxide ( $\mathrm{ZnO})$ were used as received. Merck Specialties Private Limited, India made Toluene and Diethylene glycol (DEG) were purchased and used.

\subsection{Methods}

\subsubsection{Modification of nanosilica with vulcanizing accelerator SIPX}


$5 \mathrm{~g}$ SIPX was dissolved in $50 \mathrm{~mL}$ of isopropyl alcohol and to this solution, $10 \mathrm{~g}$ of nanosilica (dried at $100{ }^{\circ} \mathrm{C}$ for 6 hours) was added. This mixture was heated at $80{ }^{\circ} \mathrm{C}$ for 24 hours with continuous stirring. After the reaction, soxhlet extraction of the reaction mixture was carried out using isopropyl alcohol for 8 hours to remove unreacted SIPX. This sample was vacuum dried at $50{ }^{\circ} \mathrm{C}$ for 3 hours to obtain SIPX modified nanosilica (SIPX-NS).

\subsubsection{Composites Preparation}

Thermo Haake Polylab with a rotor speed of $60 \mathrm{rpm}$ maintained at $70{ }^{\circ} \mathrm{C}$ was used for compounding as per ASTM D 3184. Table 1 gives the details of the formulation. Initially mastication of NR done for 3 minutes. Stearic acid, zinc oxide and styrenated phenol oil were then added. Then DEG and nanosilica were added and continued the mixing for 3 minutes. TMTD, CBS and $S$ were added and continued the mixing for 2 minutes. After this 8 minutes mixing, a laboratory size 6"x12" two roll mill was used to sheeted out the compound for 5 times (5 mm nip gap) and finally sheeted out at a $3 \mathrm{~mm}$ nip gap. Before moulding, this compound was allowed to mature for 24 hours at room temperature. A 12 "x 12 " platen size hydraulic press kept at $150{ }^{\circ} \mathrm{C} \& 150 \mathrm{~kg} / \mathrm{cm}^{2}$ pressure used to vulcanize the compounds to the optimum cure time.

Table 1. Formulation of NR mixes

\begin{tabular}{|c|c|c|c|c|c|}
\hline \multirow{2}{*}{$\begin{array}{l}\text { Ingredients * } \\
(\mathrm{phr})^{\mathrm{a}}\end{array}$} & \multicolumn{5}{|c|}{ Mix Names } \\
\hline & NR & NR & NR & NR & NR \\
\hline & Gum & $3 \mathrm{NS}$ & 3SIPX-NS & 4SIPX-NS & 5SIPX-NS \\
\hline
\end{tabular}




\begin{tabular}{cccccc}
\hline ISNR-5 & 100 & 100 & 100 & 100 & 100 \\
NS & 0 & 3 & 0 & 0 & 0 \\
SIPX-NS & 0 & 0 & 3 & 4 & 5 \\
DEG & 0 & 0.3 & 0.3 & 0.4 & 0.5 \\
\hline
\end{tabular}

* Zinc oxide 5.0, stearic acid 2.0, styrenated phenol 1.0, Tetramethylthiuram disulphide 0.2, $\mathrm{N}$-cyclohexyl-2-benzothiazole sulphenamide 0.6 and sulphur 2.5 were added in all formulations.

${ }^{a}$ parts per hundred of rubber

\subsection{Characterization methods}

Avatar 370 model Thermo Nicolet FTIR spectrometer was used to conduct Fourier transform IR analysis. JEOL (JED-2300 Model) instrument was used to perform EDX (Energy Dispersive X-ray) analysis. Malvern mastersizer-V3.30 instrument capable of measuring size between 0.1 to $1000 \mu \mathrm{m}$ and an angular range of 0.032 - 60 degrees used to measure the particle size distribution. The scanning electron microscope of JOEL (Model JSM 8390 LV) was used to analyze tensile fractured surfaces. ASTM D 573 method was used to carry out the thermal aging analysis. TA instruments (model Q-50) Thermogravimetric Analyser was used to perform thermogravimetric analysis. Samples were kept at a nitrogen atmosphere and heated from room temperature to $750{ }^{\circ} \mathrm{C}$ at a heating rate of $20{ }^{\circ} \mathrm{C} / \mathrm{min}$. Thermal conductivity was measured according to D7340 ASTM Standard using Holmarc's Lee's Disc Apparatus (Model: HOAE-LD18)

RPA 2000 model Rubber Process Analyser from Alpha Technologies, USA kept at an angle of 0.5 degree and $100 \mathrm{cpm}$ frequency was used for rheological characterization according to ASTM D 5289. Universal Testing Machine from Instron, USA was used to analyze the stress-strain properties of samples as per ASTM D 412. Test specimen un-nicked at $90^{\circ}$ angle 
was used for the tear resistance test according to ASTM D 624. Shore A type Durometer was used to measure the hardness of samples according to ASTM D 2240. Bariess DIN abrader, Germany was used to test abrasion resistance as per ASTM D 5963. According to ASTM D 297 specific gravity was measured using Densimeter. ASTM D 395 standard is used to measure compression set with $9.5 \mathrm{~mm}$ spacer thickness. Goodrich flexometer, Dynisco, USA was used to determine the heat build-up analysis as per ASTM D 623. Rebound resilience was measured according to ASTM D 7121 using Wallace Dunlop Tripsometer.

The equation below is used to calculate rebound resilience percentage (RB)

$\mathrm{RB} \%=\frac{1-\operatorname{Cos}(\text { angle of rebound })}{1-\operatorname{Cos}(\text { original angle })} \mathrm{X} 100 \ldots \ldots \ldots \ldots \ldots \ldots$

Demattia flexing machine was used to check flex cracking and crack growth of the samples as per ASTM D 430 and ASTM D 813 respectively.

Following equation was used to determine the tensile retention percentage:

Tensile retention $\%=\frac{\text { Tensile strengh after aging }}{\text { Tensile strength before aging }} \mathrm{X} 100 \ldots \ldots \ldots \ldots . .2$

Swelling of samples in toluene was used to measure the swelling index, mol percentage uptake and crosslink density.

For all samples, equation 3 was used to calculate the percentage solvent uptake (Qt\%)

Qt $\mathrm{mol} \%=\frac{\text { (Mass of solvent sorbed/Molar mass of solvent) }}{\text { Mass of polymer }} \mathrm{X} 100 \ldots \ldots 3$

The following equation was used to determine the swelling index.

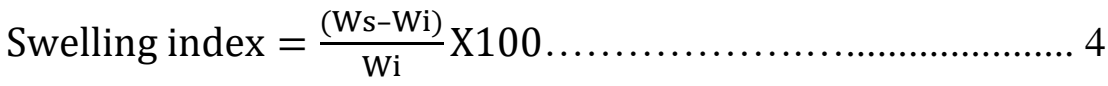

Here, Ws and Wi are the swollen and initial weight of the specimen.

Flory-Rehner equation was used to calculate the crosslink density of samples [23] 
Crosslink density $=\frac{1}{2 \mathrm{M}_{\mathrm{c}}}$

$\mathrm{M}_{\mathrm{c}}$ mentioned in the above equation is the molar mass of the sample between consecutive crosslinks. $\mathrm{M}_{\mathrm{c}}$ is calculated using equation 6 .

$\mathrm{M}_{\mathrm{c}}=-\frac{1}{2 \mathrm{~V} 2} \rho_{\mathrm{r}} \mathrm{V}_{\mathrm{s}} \mathrm{V}_{\mathrm{r}}^{\frac{1}{3}} /\left(\ln \left(1-\mathrm{V}_{\mathrm{r}}\right)+\mathrm{V}_{\mathrm{r}}+\chi \mathrm{V}_{\mathrm{r}}^{2}\right) \ldots \ldots 6$

In equation 6 , the molar volume of solvent is $V_{s}$ (for toluene $106.2 \mathrm{~cm}^{3} / \mathrm{mol}$ ), rubber density is $\rho_{\mathrm{r}}\left(0.94 \mathrm{~g} / \mathrm{cm}^{3}\right)$, the rubber volume fraction of samples at equilibrium swelling is $V_{r}$ and the interaction parameter between natural rubber and toluene is $\chi(0.3787$ from the literature [24]). Ellis and Welding equation [25] was used to calculate $V_{\mathrm{r}}$

$\mathrm{V}_{\mathrm{r}}=(d-f \mathrm{w})^{-1} /(d-f \mathrm{w}) \rho \mathrm{r}^{-1}+\mathrm{A}_{\mathrm{s}} \rho_{\mathrm{s}}^{-1}$ 7

\section{Results and discussion}

\subsection{Fourier transform infrared analysis}

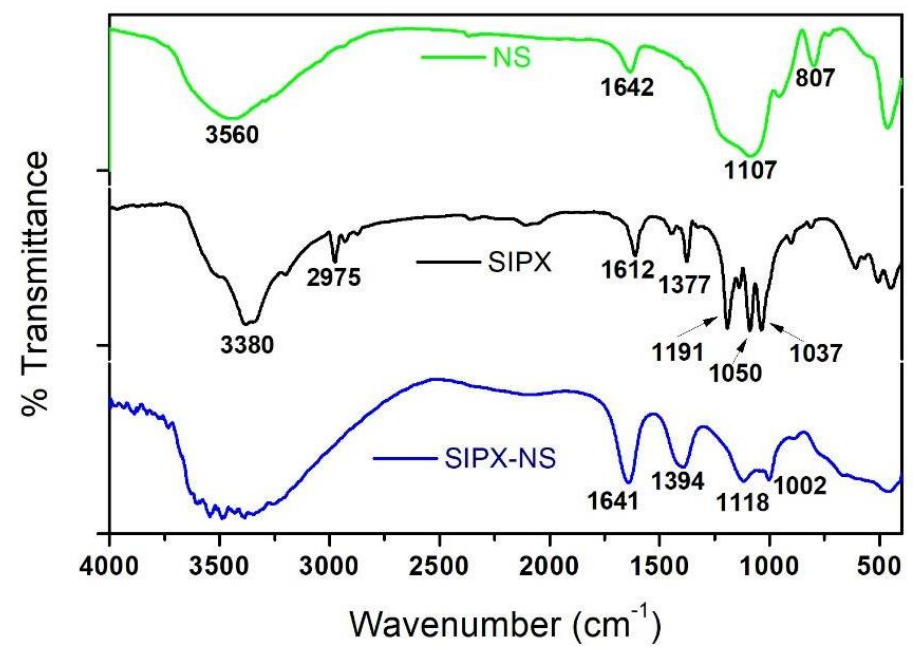

Fig.1. FTIR spectra of NS, SIPX and SIPX-NS

Figure 1 shows curves obtained from FTIR spectroscopy for samples NS, SIPX and SIPX-NS. In NS, the silanol hydroxyl groups stretching vibration and adsorbed moisture together constitute the peak at $3560 \mathrm{~cm}^{-1}$. Si-O-Si linkage symmetric and asymmetric stretching 
vibrations generate the absorbance peaks at $807 \mathrm{~cm}^{-1}$ and $1107 \mathrm{~cm}^{-1}$ respectively [16]. Bending vibrations of $-\mathrm{OH}$ groups causes a peak at $1642 \mathrm{~cm}^{-1}$. In SIPX, the $\mathrm{C}=\mathrm{S}$ stretching vibration leads to the absorption band at $1050 \mathrm{~cm}^{-1}$ and $1037 \mathrm{~cm}^{-1}$ [26]. The symmetric stretching vibration of C-O-C generates a peak at $1191 \mathrm{~cm}^{-1}$ [27]. The peaks at $1377 \mathrm{~cm}^{-1}$ correspond to symmetric deformation of the $\mathrm{C}-\mathrm{H}$ bond in $\mathrm{CH}_{3}$ group in SIPX [28]. The $\mathrm{C}=\mathrm{S}$ vibration peak of SIPX-NS at $1037 \mathrm{~cm}^{-1}$ shift towards lower wavenumbers $1002 \mathrm{~cm}^{-1}$ and peak at $1050 \mathrm{~cm}^{-1}$ shift towards higher wavenumbers $1118 \mathrm{~cm}^{-1}$ compared with those of SIPX, due to the coordinated structure of SIPX-NS.

\subsection{Elemental analysis}

The elemental analysis of the SIPX modified nanosilica shows carbon, sulphur and sodium besides silicon and oxygen. The percentage of elements are tabulated in table 2 . This confirms the successful modification of the silica with SIPX.

Table 2. Elemental analysis of SIPX-NS

\begin{tabular}{|c|c|c|c|c|c|}
\hline \multirow[b]{2}{*}{ Materials } & \multicolumn{5}{|c|}{ Elements (wt\%) } \\
\hline & $\mathrm{Si}$ & $\mathrm{O}$ & $\mathrm{C}$ & $\mathrm{Na}$ & $S$ \\
\hline NS & 49.54 & 50.46 & - & - & - \\
\hline SIPX-NS & 38.97 & 48.95 & 5.73 & 4.04 & 2.31 \\
\hline
\end{tabular}

\subsection{Dynamic light scattering analysis (DLS)}


The particle size distribution of SIPX-NS was measured using DLS. Figure 2(a) shows an average particle size of $6 \mathrm{~nm}$ for NS. The particle size of SIPX-NS is increased to $20 \mathrm{~nm}$, which could be due to the modification and also due to mild agglomeration of NS particles.

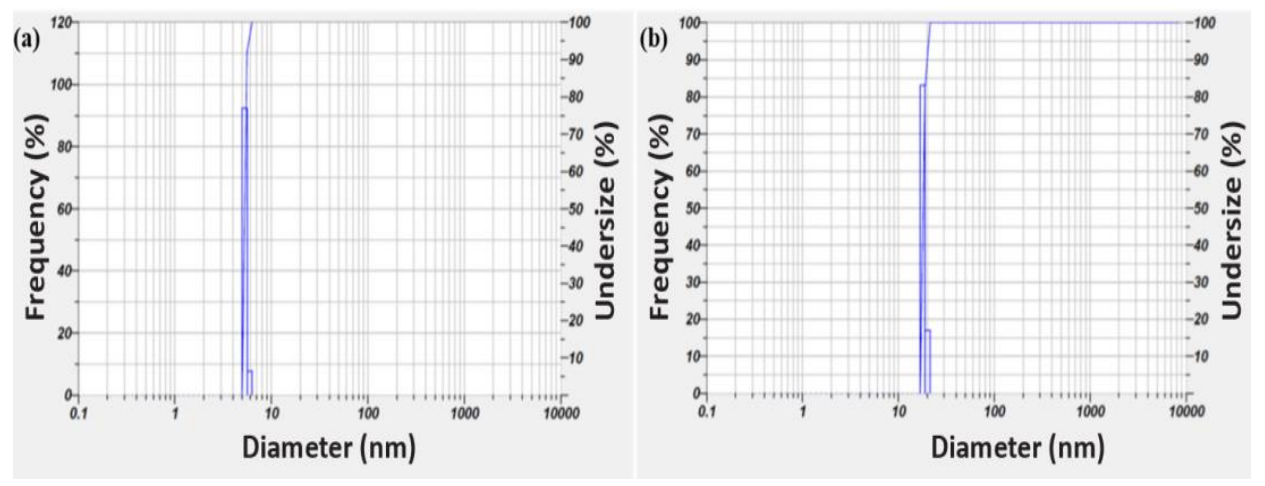

Fig. 2. Particle size distribution of (a) NS and (b) SIPX-NS

\subsection{Morphological analysis}
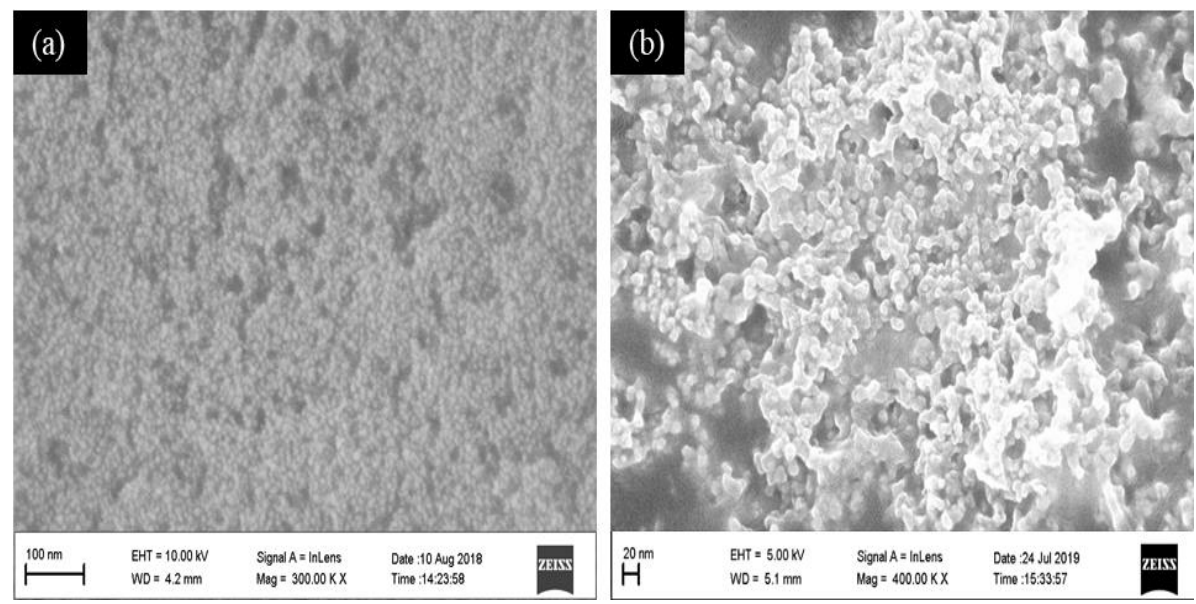

Fig.3. Scanning electron micrographs of (a) NS and (b) SIPX-NS

Scanning electron micrographs of NS and SIPX-NS are shown in figure 3. SIPX-NS particles show morphological change and higher size compared to NS. The average size of SIPX-NS measured from the micrograph is $20 \mathrm{~nm}$, whereas for NS particle size is $6 \mathrm{~nm}$. This is in agreement with the results of DLS studies. Hydrogen bonds and Van der Waals force among SIPX-NS particles lead to the agglomeration [29]. 


\subsection{Thermogravimetric analysis}

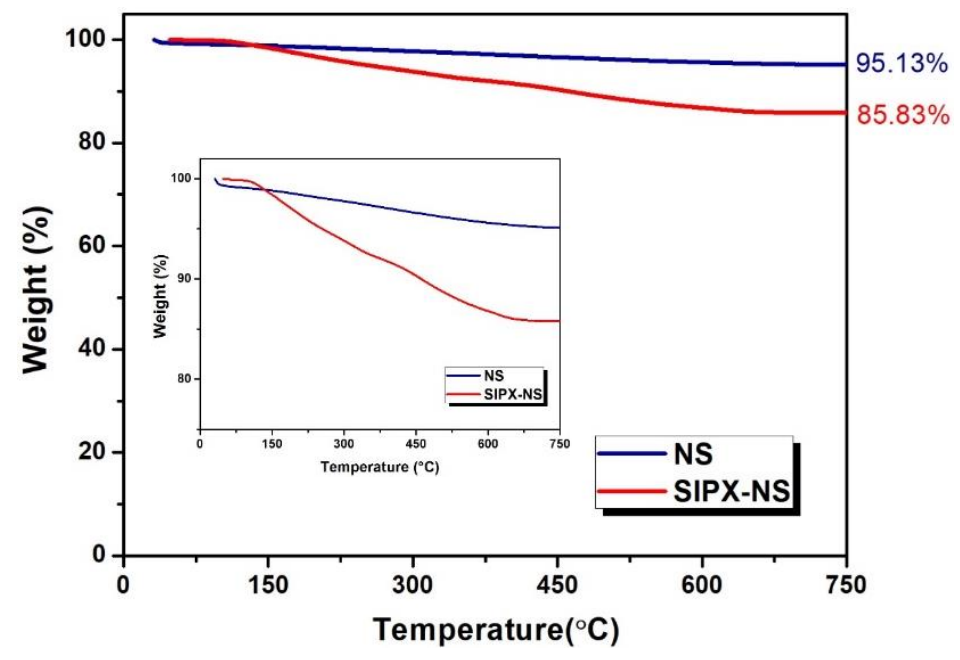

Fig.4. TGA of NS and SIPX-NS

Thermograms of NS and SIPX-NS are shown in figure 4. Within the analysis temperature 30-750 ${ }^{\circ} \mathrm{C}$, two weight loss steps exhibited by nanosilica. The release of adsorbed moisture is the reason for the initial weight loss on heating from 50 to $110{ }^{\circ} \mathrm{C}$ [30]. Silanol group's dehydration occurs between temperature $400-600{ }^{\circ} \mathrm{C}$ is the reason for second weight loss [31]. Modifying group decomposition on the temperature range between $150-600{ }^{\circ} \mathrm{C}$ is the reason $\mathrm{n}$ for the major weight loss for SIPX-NS. Very low initial weight loss of SIPX-NS between 50$110^{\circ} \mathrm{C}$ is due to the increase in the hydrophobic character of silica by the presence of an organic modifying group. Analysis of percentage residue confirmed the presence of $9.3 \mathrm{wt} \%$. of SIPX on silica particles. 


\subsection{Cure characteristics of NR composites}

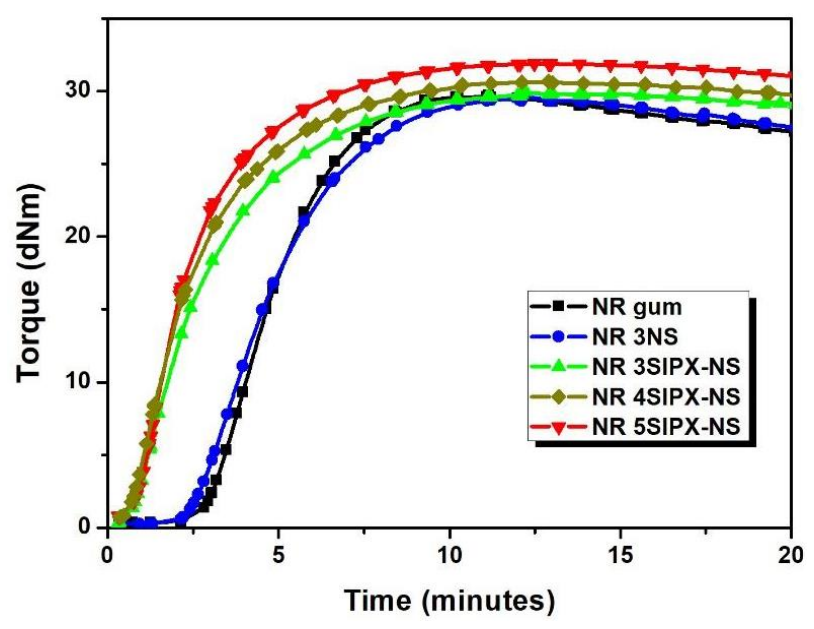

Fig.5. NR composites cure behavior

Figure 5 illustrates the cure charcteristics of natural rubber composites. Table 3 provides the cure parameters. The surface property, concentration and nature of filler influence the cure behavior of composites [32]. Compared to NR SIPX-NS composites, scorch and cure time of NR gum and NR 3NS composites are higher. Silica particles adsorption of curatives leads to an increase in cure time for NR 3NS composite [33]. Lowering of NR SIPX-NS composites optimum cure time $\left(t_{90}\right)$ is due to the reduction in surface hydroxyl groups of nanosilica and also the accelerating effect of SIPX present on the modified silica. The scorch time ( $\left.\mathrm{ts}_{2}\right)$ of modified nanosilica composites is drastically reduced due to the accelerating efficiency of SIPX. Reduction in scorch time indicates that the NR SIPX-NS composites have lower processibility. The torque values are increased with increasing SIPX-NS concentration due to the better crosslink density of composites, as indicated in table 3. 
Table 3. NR composites rheological data

\begin{tabular}{|c|c|c|c|}
\hline $\begin{array}{l}\text { Name of } \\
\text { sample }\end{array}$ & $\begin{array}{c}\mathrm{ts}_{2} \\
\text { (Minutes) }\end{array}$ & $\begin{array}{c}\text { t90 } \\
\text { (Minutes) }\end{array}$ & $\begin{array}{c}\mathrm{M}_{\mathrm{H}}-\mathrm{M}_{\mathrm{L}} \\
(\mathrm{dNm})\end{array}$ \\
\hline NR gum & 3.04 & 7.31 & 29.39 \\
\hline NR 3NS & 2.65 & 7.94 & 29.45 \\
\hline NR 3SIPX-NS & 0.89 & 6.68 & 29.62 \\
\hline NR 4SIPX-NS & 0.85 & 6.09 & 29.94 \\
\hline NR 5SIPX-NS & 0.93 & 5.78 & 31.12 \\
\hline
\end{tabular}

$\mathrm{M}_{\mathrm{H}}$ - maximum torque and $\mathrm{M}_{\mathrm{s}}-$ minimum torque

\subsection{Stress-Strain behaviour of NR composites}

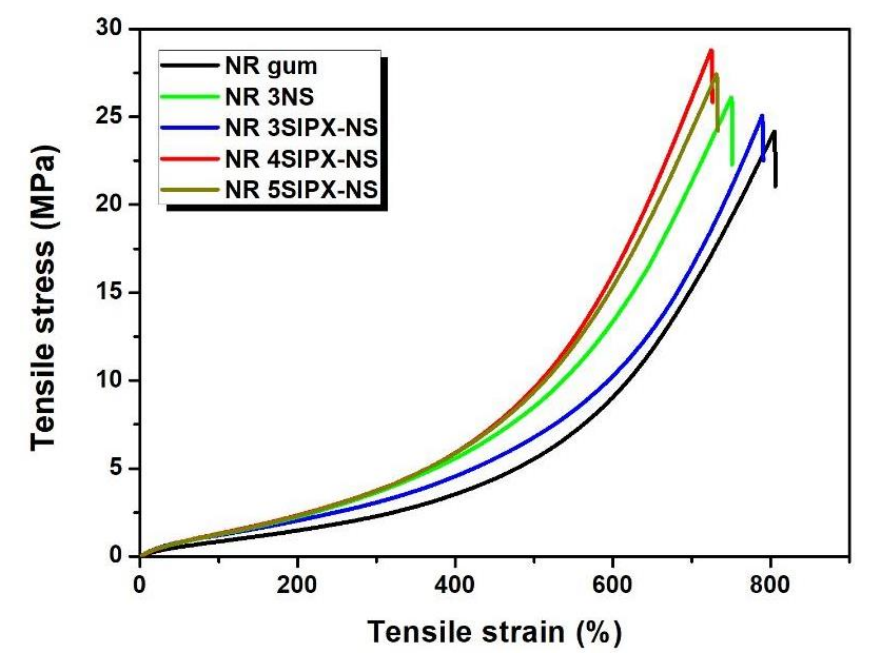

Fig.6. Tensile stress-strain curves obtained for NR composites

Figure 6 shows the stress-strain behavior obtained for all NR composites. Higher tensile strength is obtained for NR 4SIPX-NS compared to all other composites. Better rubber and filler interaction is the reason for the higher tensile strength. At a higher concentration of SIPXNS, aggregation of silica particles causes poor interaction between filler and rubber [34]. NR 
3NS composite showed maximum tensile strength [35]. NR 4SIPX-NS shows a $10 \%$ and $24 \%$ increase in tensile strength compared to NR 3NS composite and NR gum compound respectively.

Elongation at break percentage was found to be decreased with an increase in silica concentration. This is because of the restriction in the movement of polymer chains by the presence of non-deformable silica particles [36]. An increase in modified nanosilica concentration leads to an increase in tear strength and modulus at $300 \%$ elongation. This indicates that silica acts as a reinforcing filler. Elongation at break, tensile strength, modulus at $300 \%$ elongation and tear strength obtained for natural rubber composites are given in table 4. The concentration of filler, particle size and its dispersion affect the tensile strength and modulus of the composites.

Table 4. Tensile and tear properties of NR composites

\begin{tabular}{lcccc}
\hline $\begin{array}{c}\text { Name of } \\
\text { sample }\end{array}$ & $\begin{array}{c}\text { Tensile strength } \\
(\mathrm{MPa})\end{array}$ & $\begin{array}{c}\text { Elongation } \\
\text { at break } \\
(\%)\end{array}$ & $\begin{array}{c}\text { Modulus at 300\% } \\
\text { elongation } \\
(\mathrm{MPa})\end{array}$ & $\begin{array}{c}\text { Tear } \\
\text { strength } \\
(\mathrm{N} / \mathrm{mm})\end{array}$ \\
\hline NR gum & $23.35 \pm 0.8$ & $804 \pm 15$ & $2.29 \pm 0.25$ & $34.90 \pm 0.9$ \\
NR 3NS & $26.20 \pm 0.3$ & $751 \pm 16$ & $3.64 \pm 0.13$ & $43.62 \pm 1.2$ \\
NR 3SIPX-NS & $25.45 \pm 0.2$ & $790 \pm 8$ & $3.07 \pm 0.28$ & $44.71 \pm 1.4$ \\
NR 4SIPX-NS & $28.9 \pm 0.33$ & $726 \pm 14$ & $3.74 \pm 0.03$ & $45.94 \pm 1.5$ \\
NR 5SIPX-NS & $27.52 \pm 0.26$ & $732 \pm 21$ & $3.72 \pm 0.07$ & $46.05 \pm 1.8$ \\
\end{tabular}

The tensile properties of the composites are studied after aging at $100{ }^{\circ} \mathrm{C}$ for 24 hours, as it is very important to evaluate the performance in practical applications. The percentage retention of the tensile strength is shown in figure 7. NR gum shows lower retention compared to nanosilica filled composites. Luo et al. [37] observed a similar result while studying the 
effect of silica and antioxidant on NR composites. NR 4SIPX-NS shows excellent tensile retention in comparison with all other natural rubber composites.

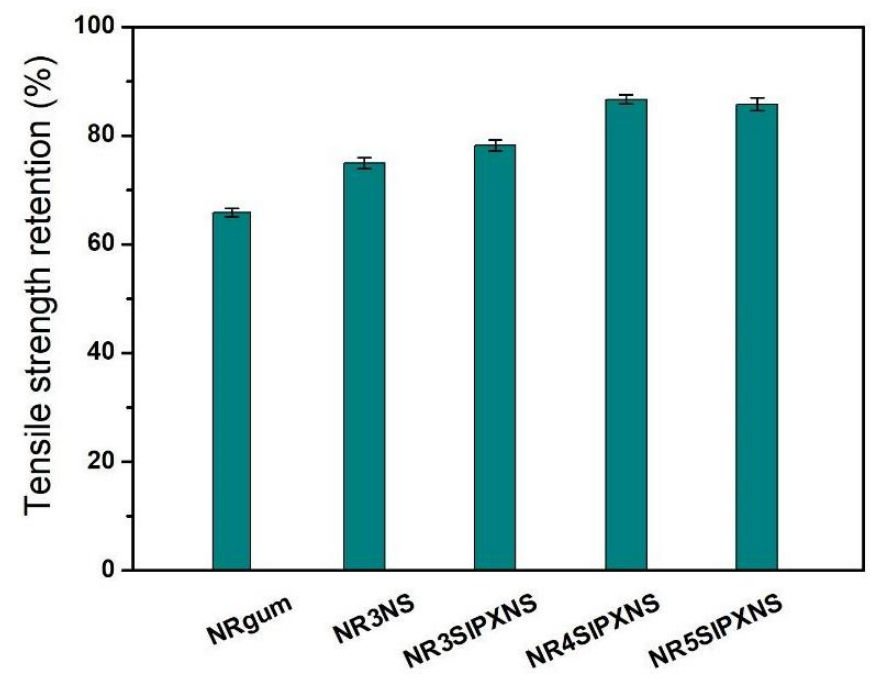

Fig.7. Retention of tensile strength of NR composites

\subsection{Other technological properties of NR composites}

Table 5 includes the tabulated values of other technological properties of NR composites. Composites showed an increase in hardness with the increase of filler loading. This is allied with the modulus increase and crosslink density increase [38] of the composites.

The abrasion resistance of rubber vulcanizates depends on several factors such as filler particle size, structure, surface activity, and filler-rubber interaction [39]. The reduction in abrasion loss for NR SIPX-NS composites attributed to the improvement in service life due to the good interaction between the matrix and filler and better filler dispersion.

The ability of a material to recover from an applied continuous strain is measured in compression set analysis. Percentage of dynamic compression set and compression set values found to be increased with the increase in nanosilica concentration as silica is a non-resilient reinforcing filler [35]. With the increase in modulus of the composite, more restriction in polymer chain mobility occurred even after the applied stress removal. This is confirmed from modulus values which show a linear relationship with the compression set. 
In the heat build-up test, the dissipation of energy occurs as heat because of the friction among filler particles and between rubber matrix and filler under cyclic deformation [40]. With the increase in filler loading heat build-up of composites found to be increased. This causes a rise in fatigue failure and leads to inferior mechanical properties of the composites [41]. There is no significant change in heat build-up for NR 4SIPX-NS and NR 3NS samples as the modification improves the filler dispersion in the rubber matrix.

Table 5. Technological properties of NR composites

\begin{tabular}{lcccccc}
\hline Sample name & $\begin{array}{c}\text { Abrasion } \\
\text { loss (cc) }\end{array}$ & $\begin{array}{c}\text { Hardness } \\
\text { (Shore A) }\end{array}$ & $\begin{array}{c}\text { Dynamic } \\
\text { compress- } \\
\text { ion set }(\%)\end{array}$ & $\begin{array}{c}\text { Heat build- } \\
\text { up }\left({ }^{\circ} \mathrm{C}\right)\end{array}$ & $\begin{array}{c}\text { Compre- } \\
\text { ssion set } \\
(\%)\end{array}$ & $\begin{array}{c}\text { Rebound } \\
\text { resilience } \\
(\%)\end{array}$ \\
\hline NR gum & $0.32 \pm 0.01$ & $38 \pm 1$ & $2.3 \pm 0.1$ & $1 \pm 0$ & $25.6 \pm 0.2$ & $78 \pm 3$ \\
NR 3NS & $0.27 \pm 0.02$ & $44 \pm 0.5$ & $4.65 \pm 0.1$ & $12 \pm 1$ & $28.4 \pm 0.1$ & $68 \pm 2$ \\
NR 3SIPX-NS & $0.28 \pm 0.05$ & $42 \pm 0.5$ & $4.75 \pm 0.2$ & $11 \pm 2$ & $28.5 \pm 0.25$ & $68 \pm 1$ \\
NR 4SIPX-NS & $0.23 \pm 0.01$ & $44 \pm 0.5$ & $7.2 \pm 0.2$ & $13 \pm 1$ & $34.91 \pm 0.17$ & $65 \pm 2$ \\
NR 5SIPX-NS & $0.22 \pm 0.01$ & $45 \pm 0.5$ & $7.2 \pm 0.3$ & $15 \pm 2$ & $35.48 \pm 0.2$ & $63 \pm 1$ \\
\hline
\end{tabular}

Table 6 shows the initial flex crack and crack growth of the NR silica composites. Resistance to flex crack and crack growth is the essential dynamic properties required for the rubber products used for dynamic applications. Flex crack resistance of the NR composites mainly depends on the dispersion of filler, nature of crosslink network and concentration and mechanical oxidative aging (antidegradent present) [42][43]. Modified nanosilica filled NR composites showed higher resistance to flex cracking and crack growth compared to unmodified nanosilica filled NR composite. This improved resistance may be due to the presence of long hydrocarbon chains in SIPX-NS, which helped for the better dispersion of nanosilica and improved crosslinking [44]. The lower value for both flex cracking and crack growth resistance for unmodified nanosilica NR composite is due to the agglomerated 
nanosilica particles and rigid interaction of nanosilica with NR. The maximum resistance obtained for NR 4SIPX-NS composite as because of the reason that the sulphur-accelerator ratio becomes optimum at this concentration [45].

Tear strength and fatigue life are interconnected as both are related to the breaking energy of the composite [46]. The relationship between crack initiation and tear strength is plotted in figure 8 . The plot implies that the factors contributing to improving tear strength may be the same as that are contributing to crack initiation resistance. The crack initiation cycles of NR 5SIPX-NS was lower compared to NR 4SIPX-NS due to the denser crosslink formation [46], as tabulated in table 3 .

Table 6. Flex cracking resistance of NR composites

\begin{tabular}{ccc}
\hline \multirow{2}{*}{ Sample name } & \multicolumn{2}{c}{ Flex crack (kilocycles) } \\
\cline { 2 - 3 } & Initiation & Crack growth \\
\hline NR 3NS & 45 & 62 \\
NR 3SIPX-NS & 47 & 66 \\
NR 4SIPX-NS & 51 & 77 \\
NR 5SIPX-NS & 50 & 74 \\
\hline
\end{tabular}




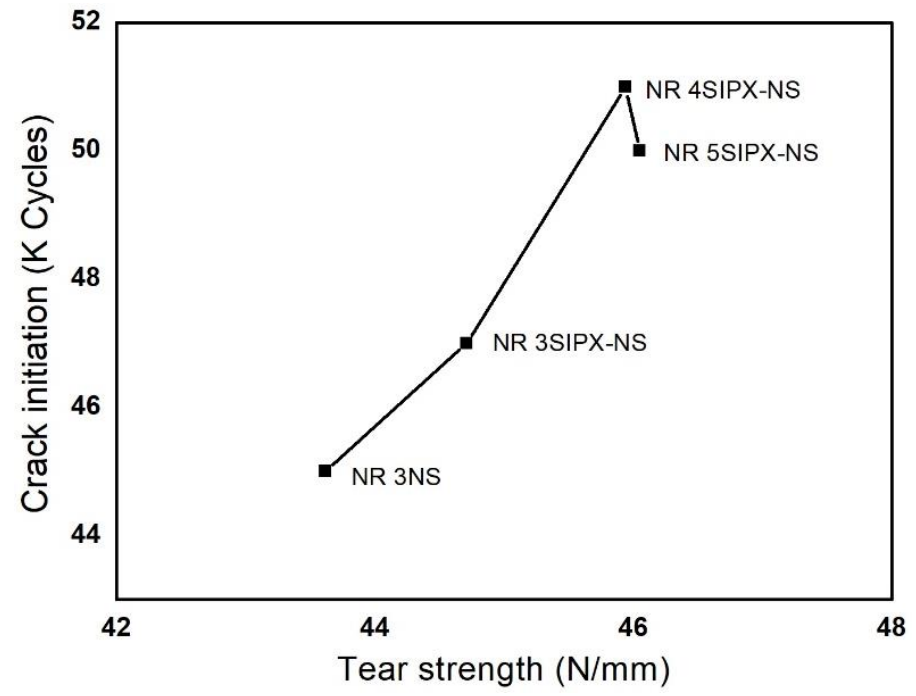

Fig.8. Relationship between tear strength and crack initiation of NR nanocomposites

\subsection{Morphology of NR composites}

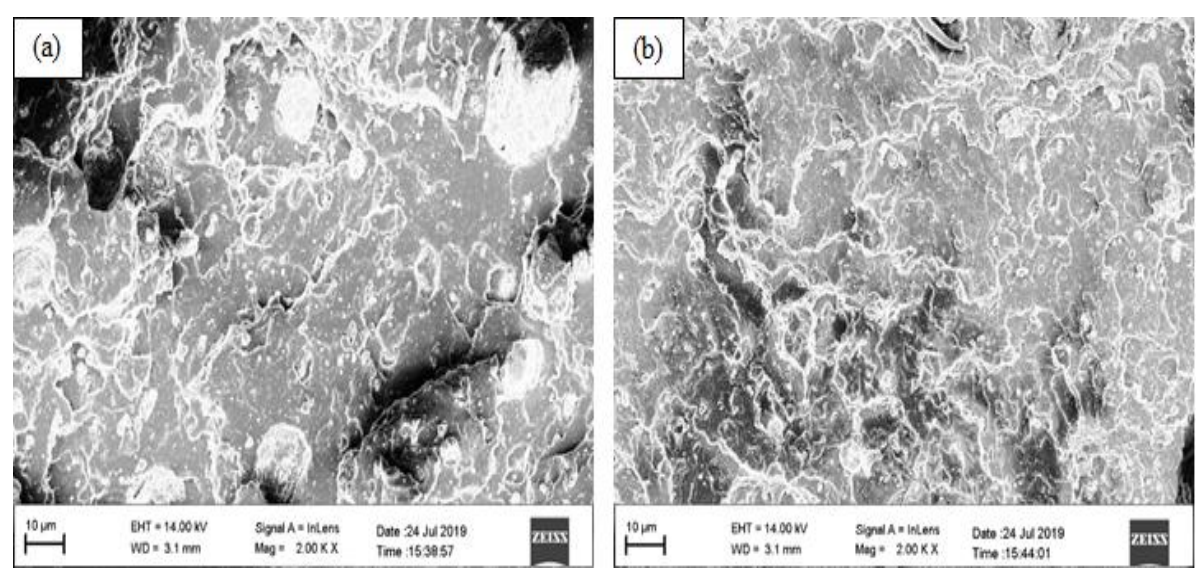

Fig.9. FESEM images of NR 3NS and NR 4SIPX-NS composites

The dispersion of filler in the polymer matrix determines composite samples of ultimate properties. Stress concentration points developed inside the composites due to aggregation of particulate fillers lead to inferior properties while nanoparticles uniform distribution enhances the properties [4]. A little roughness and few agglomerates of silica present on NR 3NS tensile fractured surface (figure 9(a)) indicate that the interfacial interaction between nanosilica and NR is less. NR 4SIPX-NS composite shown in figure 9(b) is rugged with undulations and uniform filler dispersion, indicating that the matrix could transfer the applied stress to the nanosilica during the tensile test. 


\subsection{Thermal stability of NR nanosilica composites}

Figure 10 shows the thermogravimetric curves obtained for the composite samples with nanosilica, modified nanosilica and gum compound. Natural rubber composite samples and gum compound showed a single step degradation pattern. The initiation of this single step degradation occurs by the thermal C-C bond chain scission followed by the hydrogen transfer at the scission site [47]. NR gum showed $T_{\text {on }}$ (degradation temperature at $10 \%$ wt. loss) at 325 ${ }^{\circ} \mathrm{C} .3 \mathrm{phr}$ nanosilica addition in NR increased $T_{\text {on }}$ by $3{ }^{\circ} \mathrm{C}$ while 4 SIPX-NS had no significant change due to the initial decomposition of adsorbed SIPX on nanosilica particles. The maximum degradation temperature and temperature at $50 \%$ degradation $\left(\mathrm{T}_{50}\right)$ of both $\mathrm{NR}$ 4SIPX-NS and NR 3NS samples were the same and were $4{ }^{\circ} \mathrm{C}$ higher than the gum compound. The degradation of NR depends upon the nature of the metal ion present, the concentration of xanthate used etc. [48]. As the amount of xanthate in SIPX-NS is low, the composite with SIPX-NS has no significant effect on thermal properties. The thermal degradation characteristics are shown in table 7.

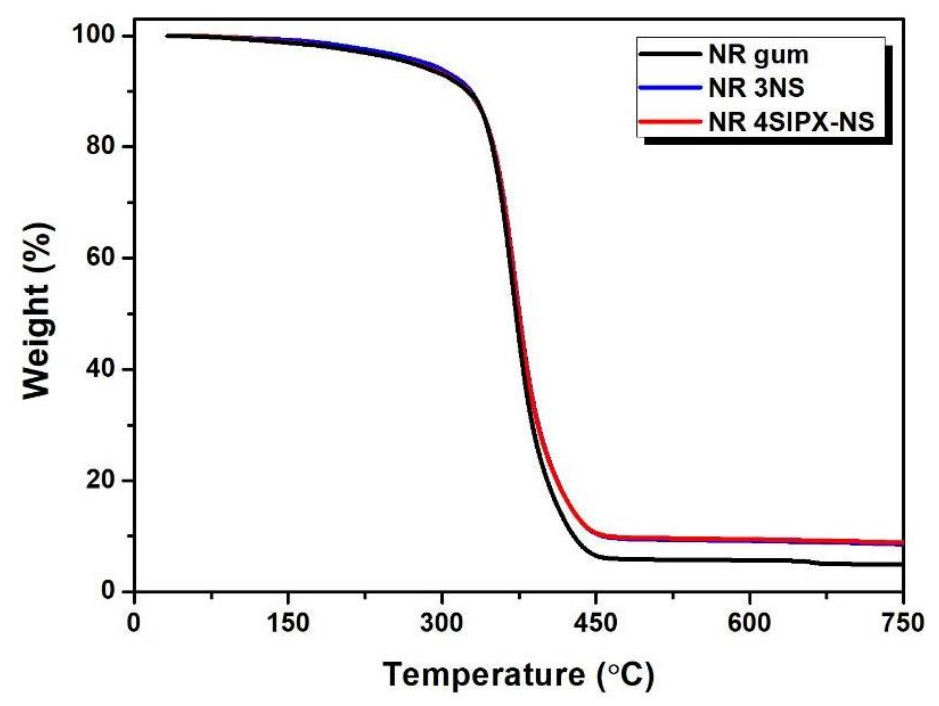

Fig.10. TG analysis of NR 4SIPX-NS, NR 3NS and NR gum 
Table 7. Data from TG analysis

\begin{tabular}{lcccc}
\hline \multirow{2}{*}{$\begin{array}{c}\mathrm{T}_{\text {on }}, \\
\text { Onset } \\
\text { sample }\end{array}$} & $\begin{array}{c}T_{\max }, \\
\text { Maximum } \\
\text { degradation } \\
\text { temperature } \\
\left({ }^{\circ} \mathrm{C}\right)\end{array}$ & $\begin{array}{c}\text { Tegradation } \\
\text { temperature } \\
\left({ }^{\circ} \mathrm{C}\right)\end{array}$ & $\begin{array}{c}\text { Temperature } \\
\text { at } 50 \%\end{array}$ & $\begin{array}{c}\text { Residue at } \\
\text { degradation } \\
\left({ }^{\circ} \mathrm{C}\right)\end{array}$ \\
\hline NR Gum & 325 & 368 & 372 & \\
NR 3NS & 328 & 372 & 375 & 8.92 \\
NR 4SIPX-NS & 326 & 372 & 375 & 8.87 \\
\hline
\end{tabular}

\subsection{Thermal conductivity of NR composites}

Thermal conductivity data for NR gum, NR 3NS and NR 4SIPX-NS composites are shown in table 8 . Thermal conductivity of polymers influenced by the incorporation of fillers [49]. The filler nature, orientation, dispersion in the matrix, volume fraction and thermal conductivity of the filler are the major parameters contributing to the thermal conductivity of composites [50]. Thermal conductivity values of NR nanosilica composites found to slightly higher compared to NR gum as nanosilica has a low value of thermal conductivity [51]. Minor enhancement in thermal conductivity of NR 4SIPX-NS composite compared to NR 3NS composite may be due to the better interaction, which is beneficial for the transmission of a phonon with decreased phonon scattering [52]. 
Table 8. Thermal conductivity of NR composites

\begin{tabular}{lc}
\hline $\begin{array}{l}\text { Name of } \\
\text { sample }\end{array}$ & $\begin{array}{r}\text { Thermal conductivity } \\
\left(\mathrm{Wm}^{-1} \mathrm{k}^{-1}\right)\end{array}$ \\
\hline NR Gum & 0.153 \\
NR 3NS & 0.172 \\
NR 4SIPX-NS & 0.174 \\
\hline
\end{tabular}

\subsection{Swelling behaviour and Crosslink density of NR silica composites}

Rubber-filler interaction and chemical crosslinks inside the vulcanized composites definitely affect the crosslink density [53]. Solvent molecular size, mobility of polymer chains and free volume inside the composite are the main factors that affect the transport of solvent through rubber matrix. Table 9 shows the tabulated values of the swelling index and crosslink density of composites samples. NR composites showed a decrease in solvent up-take with the increase in silica concentration. Compared to the NR 4SIPX-NS composite NR 3NS sample showed higher toluene up-take. This is due to better silica-rubber interactions and uniform filler dispersion in NR 4SIPX-NS composite. Transportation of solvent molecules through the NR matrix restricted by the uniformly distributed SIPX-NS particles. After vulcanization mobility of the NR chains restricted by filler particles. Maximum crosslink density observed for NR 5SIPX-NS sample and the value was comparable with 4SIPX-NS containing NR composite.

Table 9. Swelling index and crosslink density of NR silica composites 


\begin{tabular}{lcc}
\hline \multicolumn{1}{c}{ Sample name } & Crosslink density & Swelling \\
& $\left(10^{-5} \mathrm{~mol} / \mathrm{g}\right)$ & index $(\%)$ \\
NR gum & $7.4 \pm 0.1$ & $356 \pm 2$ \\
NR 3NS & $7.93 \pm 0.1$ & $337 \pm 1$ \\
NR 3SIPX-NS & $8 \pm 0.1$ & $341 \pm 1$ \\
NR 4SIPX-NS & $8.37 \pm 0.1$ & $315 \pm 2$ \\
NR 5SIPX-NS & $8.40 \pm 0.1$ & $307 \pm 1$ \\
\hline
\end{tabular}

\section{Conclusions}

Synergistic effects of the accelerator sodium isopropyl xanthate and nanosilica on thermooxidative aging resistance and cure characteristics for natural rubber were studied in this work. A simple and highly efficient modification on the surface of nanosilica was performed using sodium isopropyl xanthate. The modification was confirmed by FTIR, EDX, FESEM, DLS and TGA. Improved rheological, mechanical and aging properties were observed for the modified silica NR composite, which could be credited to the significantly improved rubberfiller interfacial interaction, higher crosslink density and dispersion. Improved interfacial interaction and dispersion of modified silica were revealed by FESEM. NR modified silica composite had high crosslinking density and hence showed high tensile strength retention and flex crack resistance. This indicates the composite has a long service life and can be used for a wide range of applications.

\section{Funding statement}

This work was not supported by any funding agencies.

\section{Conflict of Interest}

The authors have no conflicts of interest to declare that are relevant to the content of this article. 


\section{Author contributions}

P. Dileep : Conceptualization, Methodology, Visualization, Investigation. Sinto Jacob :

Writing- Original draft. C.S. Julie Chandra.: Data Curation, Resources. Midhun Dominic

C.D.: Data Curation, Resources. Poornima M P.: Data Curation, Resources. Sunil K.

Narayanankutty.: Supervision, Writing, Reviewing and Editing.

\section{Availability of data and material}

My research didn't generate any data or I reused existing data

\section{Compliance with Ethical Standards}

This article does not contain any studies involving animals or human participants performed by any of the authors.

\section{Consent to participate}

Not Applicable

\section{Consent for Publication}

Not Applicable

\section{Acknowledgments}

We thank J J Murphy Research Centre, Rubber Park India (P) Ltd., Valayanchirangara for rheological characterization and mechanical properties analysis and Department of Physics, Cochin University of Science and Technology for FESEM and EDX analysis.

\section{References}

[1] D. Hu, Z. Jia, B. Zhong, Y. Chen, Y. Luo, D. Jia (2016) A facile and green preparation of nanosilica-supported antioxidant and its reinforcement and antioxidation effect on styrene-butadiene rubber. Int J Polym Anal Charact 21: 185-197 doi:10.1080/1023666X.2016.1132125.

[2] Y. Li, B. Han, L. Liu, F. Zhang, L. Zhang, S. Wen, Y. Lu, H. Yang, J. Shen (2013) Surface modification of silica by two-step method and properties of solution styrene 
butadiene rubber (SSBR) nanocomposites filled with modified silica. Compos Sci Technol 88: 69-75 doi:10.1016/j.compscitech.2013.08.029.

[3] I. Surya, H. Ismail, A.R. Azura (2014) The comparison of alkanolamide and silane coupling agent on the properties of silica- filled natural rubber ( SMR-L ) compounds. Polym Test 40: 24-32 doi:10.1016/j.polymertesting.2014.08.007.

[4] H. Zhang, Y. Gao, F. Li, Z. Zhang, Y. Liu, G. Zhao (2016) Influence of silane coupling agents on vulcanised natural rubber: Dynamic properties and heat buildup. Plast Rubber Compos 45: 9-15 doi:10.1080/14658011.2015.1112518.

[5] J. Zheng, D. Han, S. Zhao, X. Ye, Y. Wang, Y. Wu, D. Dong, J. Liu, X. Wu, L. Zhang (2018) Constructing a Multiple Covalent Interface and Isolating a Dispersed Structure in Silica/Rubber Nanocomposites with Excellent Dynamic Performance. ACS Appl Mater Interfaces 10: 19922-19931 doi:10.1021/acsami.8b02358.

[6] B. Qiao, Y. Liang, T.J. Wang, Y. Jiang (2016) Surface modification to produce hydrophobic nano-silica particles using sodium dodecyl sulfate as a modifier. Appl Surf Sci 364: 103-109 doi:10.1016/j.apsusc.2015.12.116.

[7] H. Lei, G. Huang, G. Weng (2013) Synthesis of a new nanosilica-based antioxidant and its influence on the anti-oxidation performance of natural rubber. J Macromol Sci Part B Phys 52: 84-94 doi:10.1080/00222348.2012.695560.

[8] I. Sondi, T.H. Fedynyshyn, R. Sinta, E. Matijević (2000) Encapsulation of nanosized silica by in situ polymerization of tert-butyl acrylate monomer. Langmuir 16: 90319034 doi:10.1021/la000618m.

[9] P. Espiard, A. Guyot, J. Perez, G. Vigier, L. David (1995) Poly(ethyl acrylate) latexes encapsulating nanoparticles of silica: 3. Morphology and mechanical properties of 
reinforced films. Polymer (Guildf) 36: 4397-4403 doi:10.1016/0032-3861(95)96845Y.

[10] F. Vilmin, I. Bottero, A. Travert, N. Malicki, F. Gaboriaud, A. Trivella, F. ThibaultStarzyk (2014) Reactivity of bis[3-(triethoxysilyl)propyl] tetrasulfide (TESPT) silane coupling agent over hydrated silica: Operando IR spectroscopy and chemometrics study. J Phys Chem C 118: 4056-4071 doi:10.1021/jp408600h.

[11] L. Chen, Z. Jia, Y. Tang, L. Wu, Y. Luo, D. Jia (2017) Novel functional silica nanoparticles for rubber vulcanization and reinforcement. Compos Sci Technol 144: 11-17 doi:10.1016/j.compscitech.2016.11.005.

[12] B. Zhong, Z. Jia, D. Hu, Y. Luo, D. Jia, F. Liu (2017) Enhancing interfacial interaction and mechanical properties of styrene-butadiene rubber composites via silica-supported vulcanization accelerator. Compos Part A Appl Sci Manuf 96: 129-136 doi:10.1016/j.compositesa.2017.02.016.

[13] G. Mathew, M.Y. Huh, J.M. Rhee, M.H. Lee, C. Nah (2004) Improvement of properties of silica-filled styrene-butadiene rubber composites through plasma surface modification of silica. Polym Adv Technol 15: 400-408 doi:10.1002/pat.482.

[14] X. Wang, P. Wang, Y. Jiang, Q. Su, J. Zheng (2014) Facile surface modification of silica nanoparticles with a combination of noncovalent and covalent methods for composites application. Compos Sci Technol 104: 1-8 doi:10.1016/j.compscitech.2014.08.027.

[15] P. Weng, Z. Tang, J. Huang, S. Wu, B. Guo (2019) Promoted dispersion of silica and interfacial strength in rubber/silica composites by grafting with oniums. J Appl Polym Sci 48243- 48243. doi:10.1002/app.48243. 
[16] J. Liu, Y. Cheng, K. Xu, L. An, Y. Su, X. Li, Z. Zhang (2018) Effect of nano-silica filler on microstructure and mechanical properties of polydimethylsiloxane-based nanocomposites prepared by “inhibition-grafting” method. Compos Sci Technol 167: 355-363 doi:10.1016/j.compscitech.2018.08.014.

[17] B. Guo, F. Chen, Y. Lei, W. Chen (2010) Significantly improved performance of rubber/silica composites by addition of sorbic acid. Polym J 42: 319-326 doi:10.1038/pj.2010.4.

[18] P. Taylor, S. Attharangsan, H. Ismail, M.A. Bakar, J. Ismail (2014) The Effect of Rice Husk Powder on Standard Malaysian Natural Rubber Grade L ( SMR L ) and Epoxidized Natural Rubber ( ENR 50 ) Composites. Polym Plast Technol Eng 37-41 doi:10.1080/03602559.2011.625377.

[19] T. Xu, Z. Jia, Y. Luo, D. Jia, Z. Peng (2015) Interfacial interaction between the epoxidized natural rubber and silica in natural rubber/silica composites. Appl Surf Sci 328: 306-313 doi:10.1016/j.apsusc.2014.12.029.

[20] H. Ismail, A. Rusli, A.A. Rashid (2005) Maleated natural rubber as a coupling agent for paper sludge filled natural rubber composites. Polym Test 24: 856-862 doi:10.1016/j.polymertesting.2005.06.011.

[21] I. Gelling (1991) Epoxidised natural rubber. Prog Rubber Plast Technol 7: 271-297

[22] P. Dileep, S.K. Narayanankutty (2020) A novel method for preparation of nanosilica from bamboo leaves and its green modification as a multi-functional additive in styrene butadiene rubber. Mater Today Commun 24: 100957 doi:10.1016/j.mtcomm.2020.100957.

[23] P. J. Flory, J. John Rehner (1943) Statistical Mechanics of Crosslinked Polymer 
Networks I. Rubberlike Elasticity. J Chem Phys 11: 512-520 doi:10.1063/1.1723791.

[24] K. Boonkerd, S. Chuayjuljit, D. Abdulraman, W. Jaranrangsup (2012) Silica-rich filler for the reinforcement in natural rubber. Rubber Chem Technol 85: 1-13 doi:10.5254/1.3672114.

[25] B. Ellis, G. N. Welding (1964) Estimation, from Swelling, of the Structural Contribution of Chemical Reactions to the Vulcanization of Natural Rubber. Part II. Estimation of Equilibrium Degree of Swelling. Rubber Chem Technol 37: 563-570. doi:10.5254/1.3540348.

[26] X.-H. Wang (1996) Interfacial Electrochemistry of Pyrite Oxidation and Flotation. J Colloid Interface Sci 178: 628-637 doi:10.1006/jcis.1996.0160.

[27] H. Peng, D. Wu, M. Abdalla, W. Luo, W. Jiao, X. Bie (2017) Study of the effect of sodium sulfide as a selective depressor in the separation of chalcopyrite and molybdenite. Minerals. 7. doi:10.3390/min7040051.

[28] P. Shiny, D. P.V, J. Rani (2010) Use of sodium and potassium butyl xanthate as accelerator for room temperature prevulcanization of natural rubber latex. J Appl Polym Sci 116: 2658-2667. doi:10.1002/app.34057.

[29] C. Zhou, S. Xu, P. Pi, J. Cheng, L. Wang, J. Yang, X. Wen (2018) Polyacrylate/silica nanoparticles hybrid emulsion coating with high silica content for high hardness and dry-wear-resistant. Prog Org Coatings 121: 30-37 doi:10.1016/j.porgcoat.2018.04.001.

[30] C. Zhang, Z. Tang, B. Guo, L. Zhang (2019) Concurrently improved dispersion and interfacial interaction in rubber/nanosilica composites via efficient hydrosilane functionalization. Compos Sci Technol 169: 217-223 
doi:10.1016/j.compscitech.2018.11.016.

[31] B. Charmas, K. Kucio, V. Sydorchuk, S. Khalameida, M. Zięzio, A. Nowicka (2018) Characterization of Multimodal Silicas Using TG/DTG/DTA, Q-TG, and DSC Methods. Colloids and Interfaces 3 6. doi:10.3390/colloids3010006.

[32] C. Zhang, Z. Tang, B. Guo, L. Zhang (2018) Significantly improved rubber-silica interface via subtly controlling surface chemistry of silica. Compos Sci Technol 156: 70-77 doi:10.1016/J.compscitech.2017.12.020.

[33] C. Ryu, S.J. Kim, D. Il Kim, S. Kaang, G. Seo (2016) The Effect of Surface Area of Silicas on Their Reinforcing Performance to Styrene-butadiene Rubber Compounds. Elastomers Compos 51: 128-137 doi:10.7473/EC.2016.51.2.128.

[34] N. Mahir, H. Ismail, N. Othman (2016) Tensile, swelling and thermal aging properties of mangosteen (garcinia mangostana) peel powder filled natural rubber compounds. J Polym Mater 33: 233-243

[35] P. Dileep, S.K. Narayanankutty (2020) Styrenated phenol modified nanosilica for improved thermo-oxidative and mechanical properties of natural rubber. Polym Test 82:106302 doi:10.1016/j.polymertesting.2019.106302.

[36] K. Ahmed (2015) Hybrid composites prepared from Industrial waste: Mechanical and swelling behavior J Adv Res 6225-232 doi:10.1016/j.jare.2013.12.002.

[37] K. Luo, G. You, X. Zhao, L. Lu, W. Wang, S. Wu (2019) Synergistic effects of antioxidant and silica on enhancing thermo-oxidative resistance of natural rubber: Insights from experiments and molecular simulations. Mater Des 181: 107944 doi:10.1016/j.matdes.2019.107944.

[38] N. Rattanasom, T. Saowapark, C. Deeprasertkul (2007) Reinforcement of natural 
rubber with silica/carbon black hybrid filler. Polym Test 26: 369-377 doi:10.1016/j.polymertesting.2006.12.003.

[39] S. Sattayanurak, J.W.M. Noordermeer, K. Sahakaro, W. Kaewsakul, W.K. Dierkes, A. Blume (2019) Silica-Reinforced Natural Rubber: Synergistic Effects by Addition of Small Amounts of Secondary Fillers to Silica-Reinforced Natural Rubber Tire Tread Compounds. Adv Mater Sci Eng 1-8. doi:10.1155/2019/5891051.

[40] P. Yu, H. He, Y. Jia, T. Shenghui, C. Jian, D. Jia, Y. Luo (2016) A comprehensive study on lignin as a green alternative of silica in natural rubber composites. Polym Test doi:10.1016/j.polymertesting.2016.07.014.

[41] W. Xing, M. Tang, J. Wu, G. Huang, H. Li, Z. Lei, X. Fu, H. Li (2014) Multifunctional properties of graphene/rubber nanocomposites fabricated by a modified latex compounding method. Compos Sci Technol 99: 67-74 doi:10.1016/j.compscitech.2014.05.011.

[42] M. Walia, S. Goyal, K.K. Kapoor, S. Suneja, S. Dev (2004) Factors that affect the fatigue life of rubber: a literature survey. J Rubber Chem Technol 77: 391-412

[43] P. Yu, H. He, Y. Jia, S. Tian, J. Chen, D. Jia, Y. Luo (2016) A comprehensive study on lignin as a green alternative of silica in natural rubber composites. Polym Test 54 : 176-185 doi:10.1016/j.polymertesting.2016.07.014.

[44] P.B. Sulekha, R. Joseph, K.N. Madhusoodanan, K.T. Thomas (2002) New oligomerbound antioxidants for improved flex crack resistance and ozone resistance Polym Degrad Stab 77: 403-416 doi:10.1016/S0141-3910(02)00090-3.

[45] W. L. Cox and C. R. Parks (1966) Effect of curing systems on fatigue of natural rubber vulcanizates Am Chem Soc 785-797. doi:10.5254/1.3544883. 
[46] J.E. Mark, B. Erman, M. Roland (2013) The Science and Technology of Rubber, 4th ed., Academic Press. https://books.google.co.in/books?id=otzx0FCPyPcC.

[47] Y. Chen, Z. Peng, L.X. Kong, M.F. Huang, P.W. Li (2008) Natural rubber nanocomposite reinforced with nano silica. Polym Eng Sci 48: 1674-1677 doi:10.1002/pen.20997.

[48] R. Chandra (1981) Controlled Thermal Degradation of Natural Rubber in Dilute Solutions in the Presence \& Absence of Some Metal Isopropylxanthates. Indian J Chem $20: 1178-1181$

[49] A. Tsekmes, R. Kochetov, P. Morshuis, J.J. Smit, T. Iizuka, K. Tatsumi, T. Tanaka (2014) How different fillers affect the thermal conductivity of epoxy composites. doi:10.1109/CEIDP.2014.6995843.

[50] C. Huang, X. Qian, R. Yang (2018) Thermal conductivity of polymers and polymer nanocomposites. Mater Sci Eng R Reports 132: 1-22 doi:10.1016/j.mser.2018.06.002.

[51] V.D. Chari, D.V.S.G.K. Sharma, P.S.R. Prasad, S.R. Murthy (2013) Dependence of thermal conductivity in micro to nano silica. Bull Mater Sci 36: 517-520 doi:10.1007/s12034-013-0519-3.

[52] D. Yang, X. Kong, Y. Ni, D. Gao, B. Yang, Y. Zhu, L. Zhang (2019) Novel nitrilebutadiene rubber composites with enhanced thermal conductivity and high dielectric constant. Compos Part A Appl Sci Manuf 124: 105-447 doi:10.1016/j.compositesa.2019.05.015.

[53] J.-Y. Lee, N. Park, S. Lim, B. Ahn, W. Kim, H. Moon, H. Paik, W. Kim (2017) Influence of the silanes on the crosslink density and crosslink structure of silica-filled solution styrene butadiene rubber compounds. Compos Interfaces 24: 711-727 
doi:10.1080/09276440.2017.1267524. 
Figures

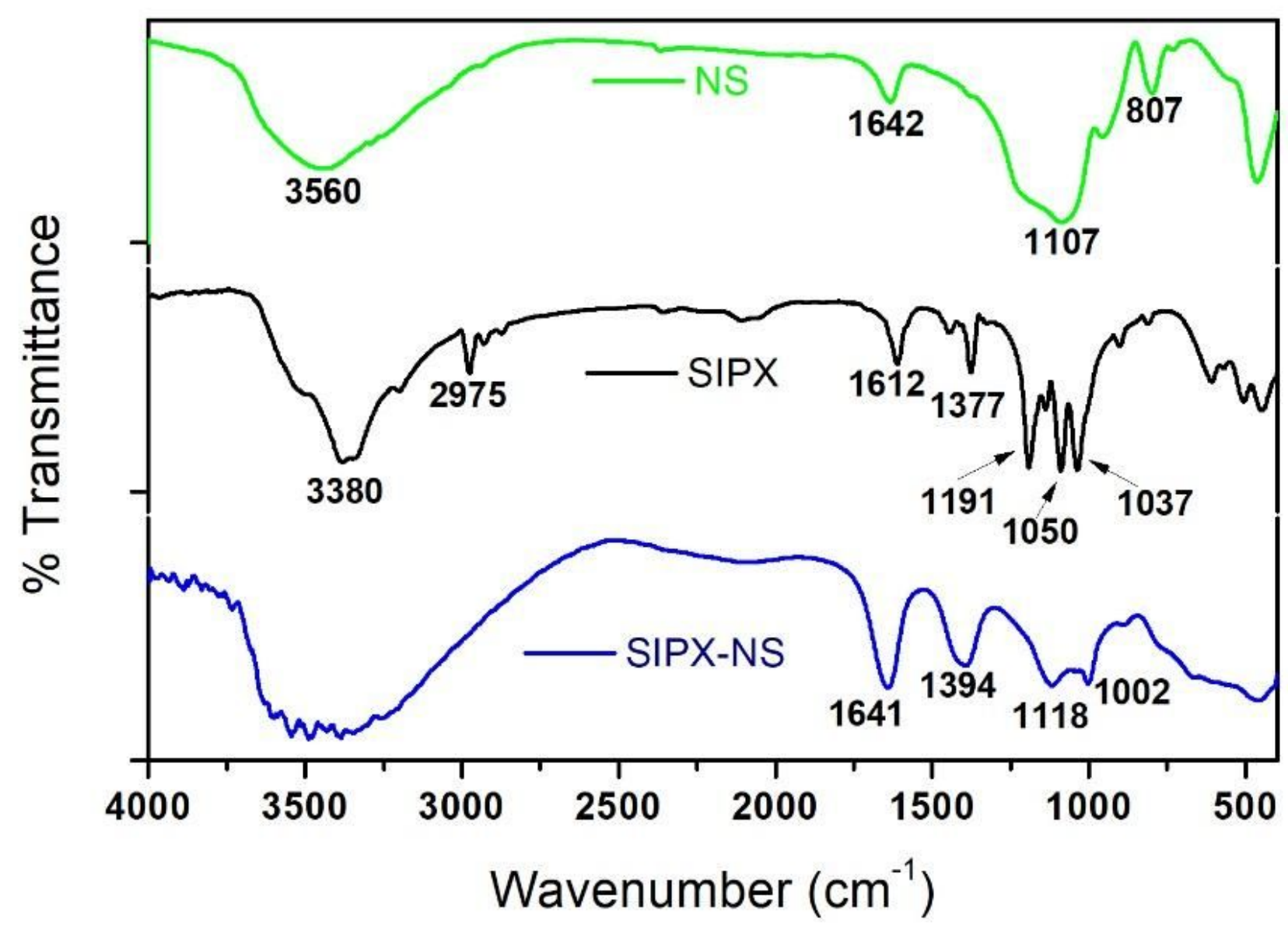

Figure 1

FTIR spectra of NS, SIPX and SIPX-NS
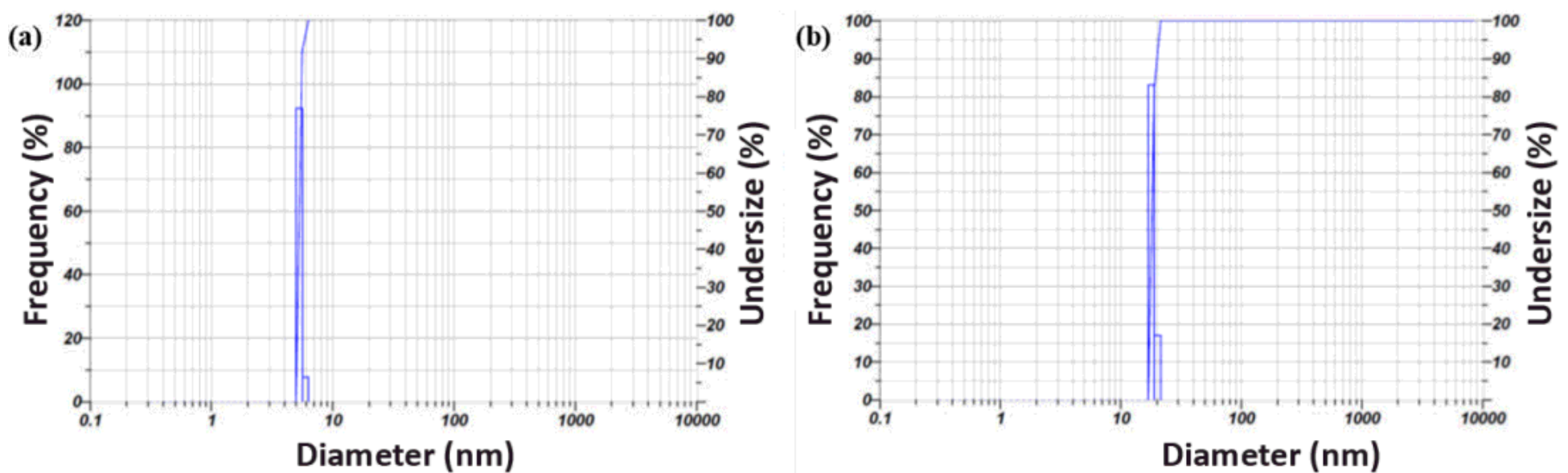
Figure 2

Particle size distribution of (a) NS and (b) SIPX-NS

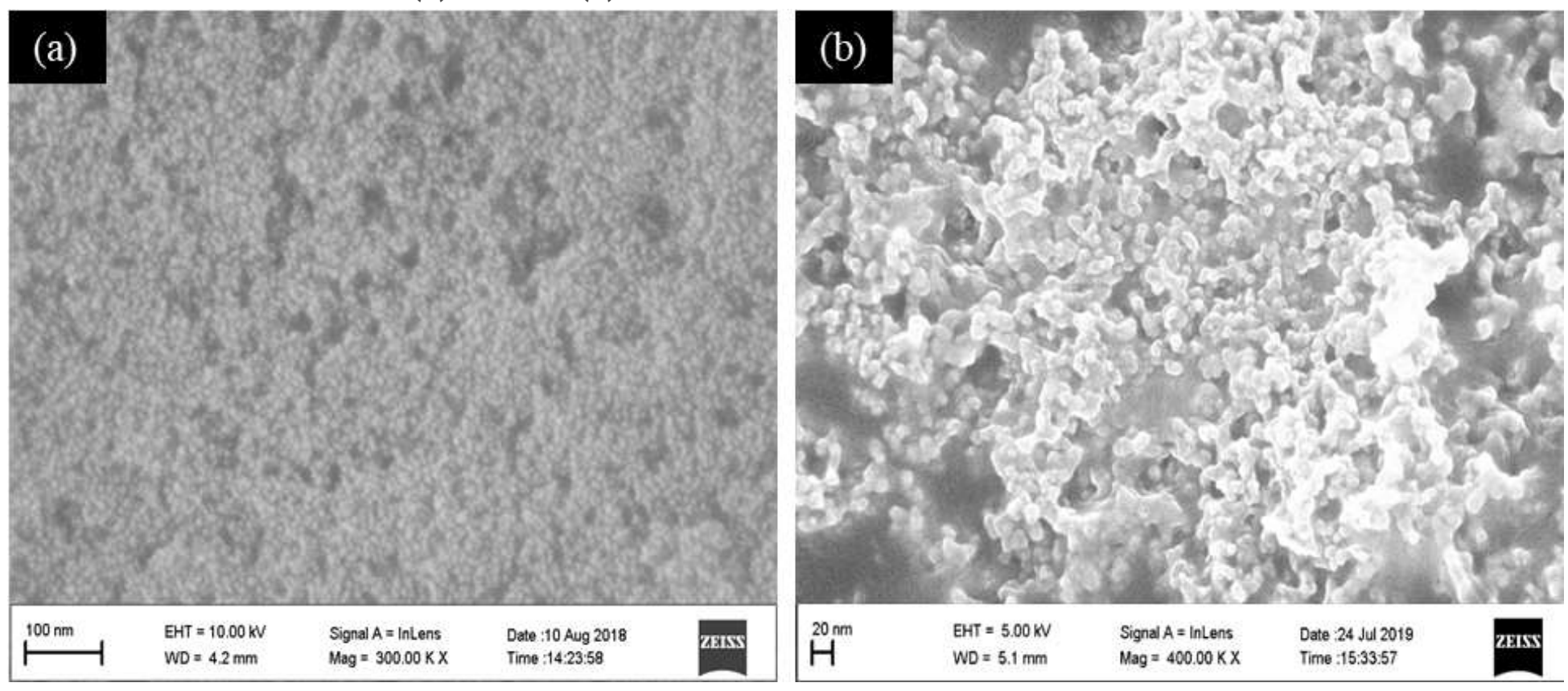

Figure 3

Scanning electron micrographs of (a) NS and (b) SIPX-NS 


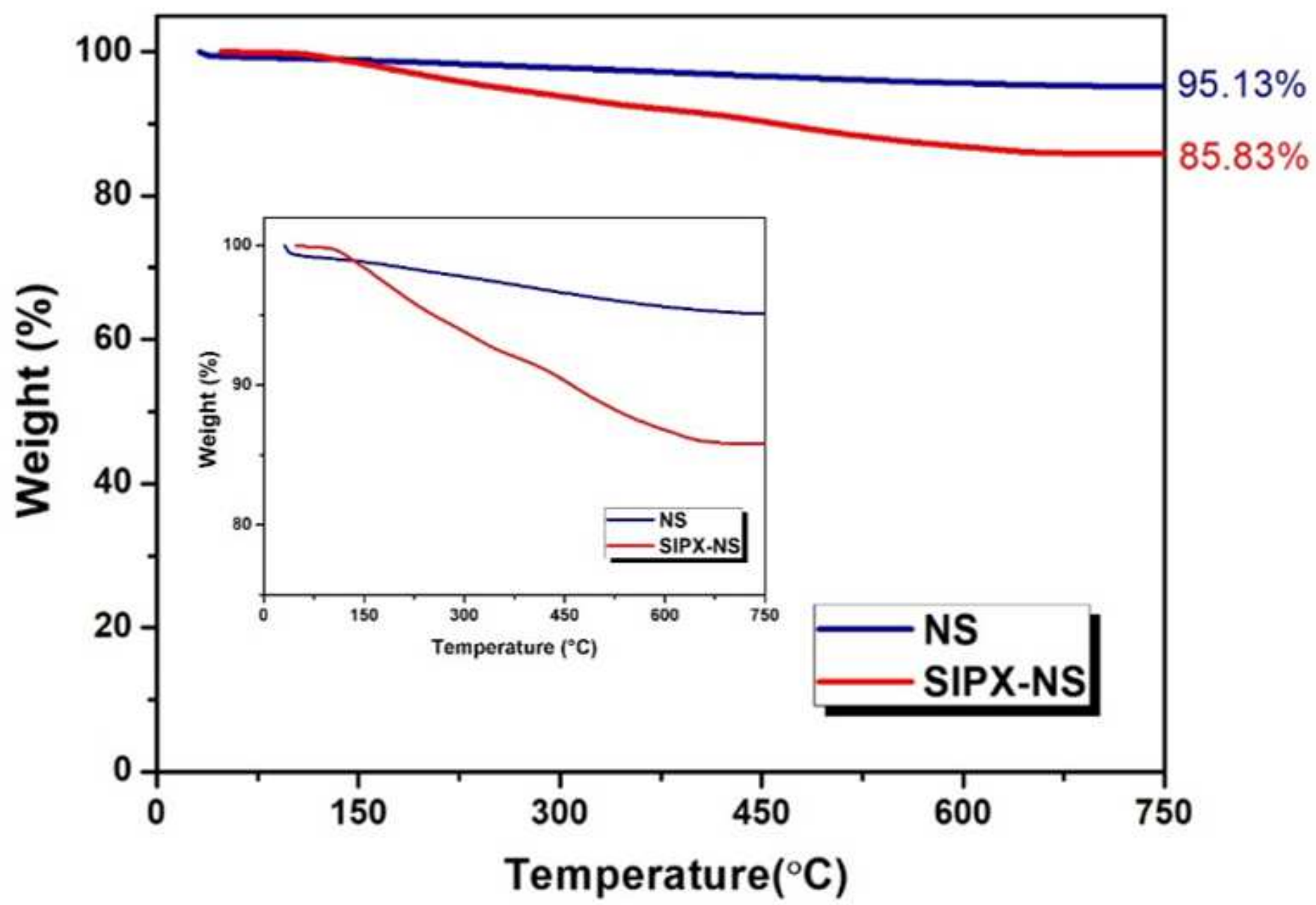

Figure 4

TGA of NS and SIPX-NS 


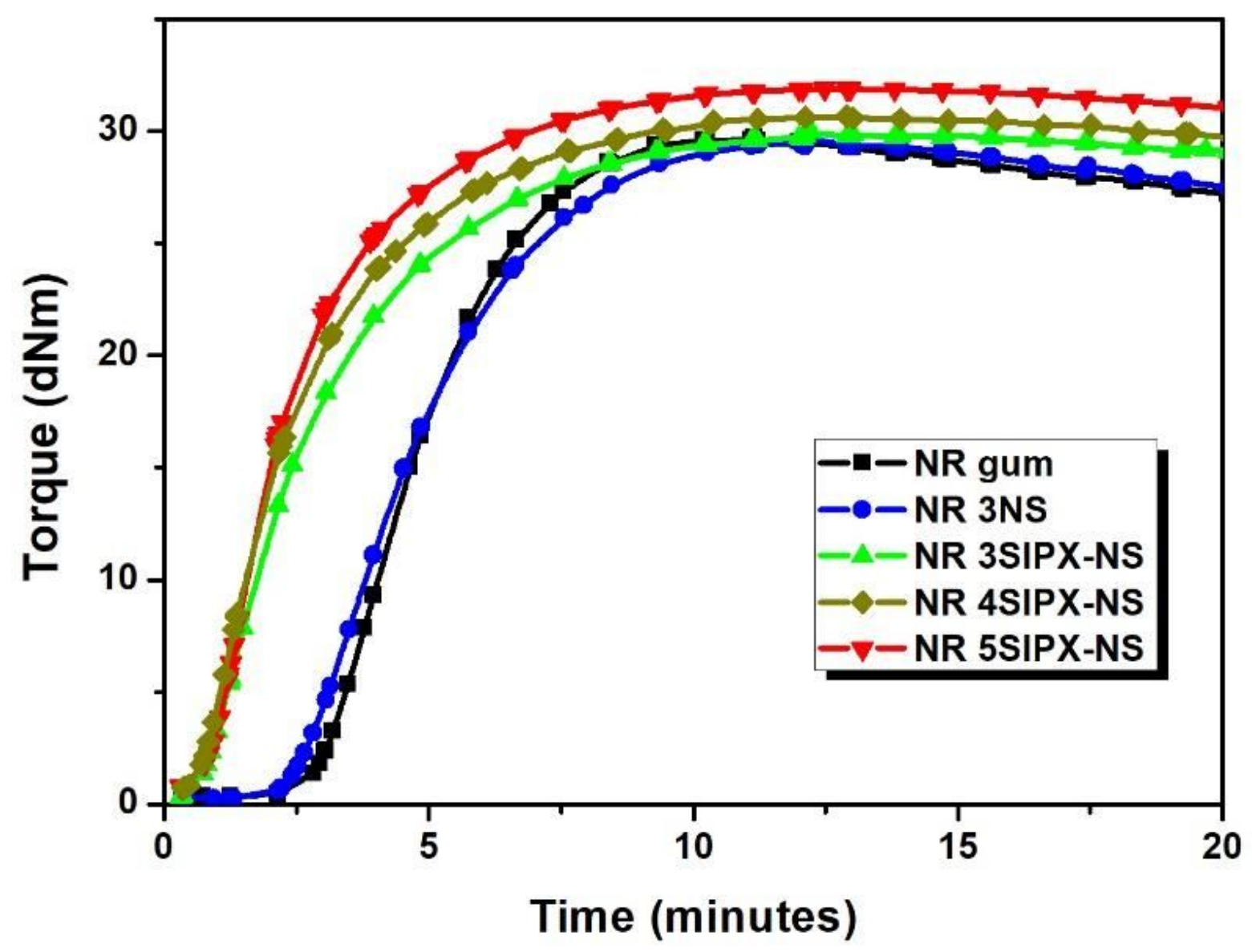

Figure 5

NR composites cure behavior 


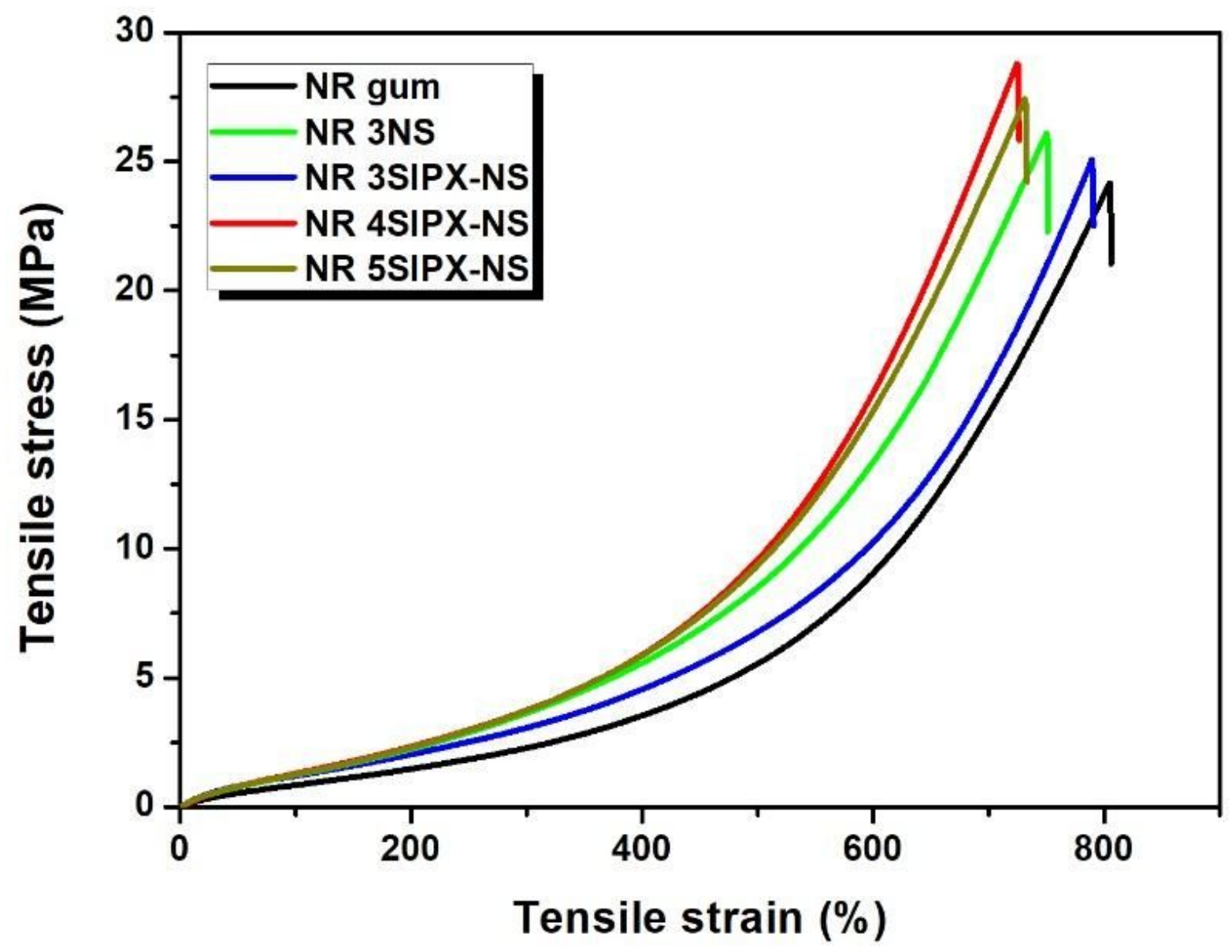

Figure 6

Tensile stress-strain curves obtained for NR composites 


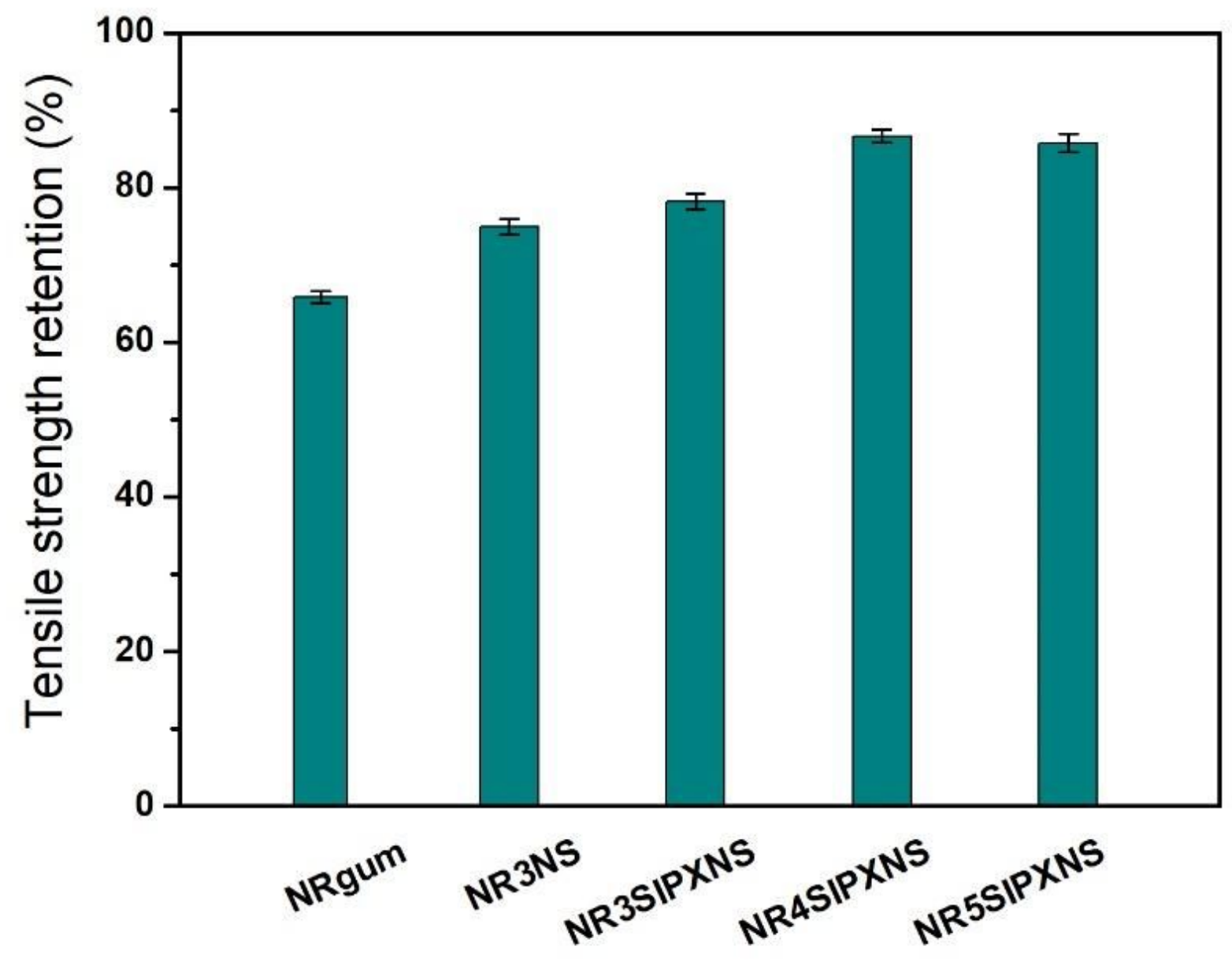

Figure 7

Retention of tensile strength of NR composites 


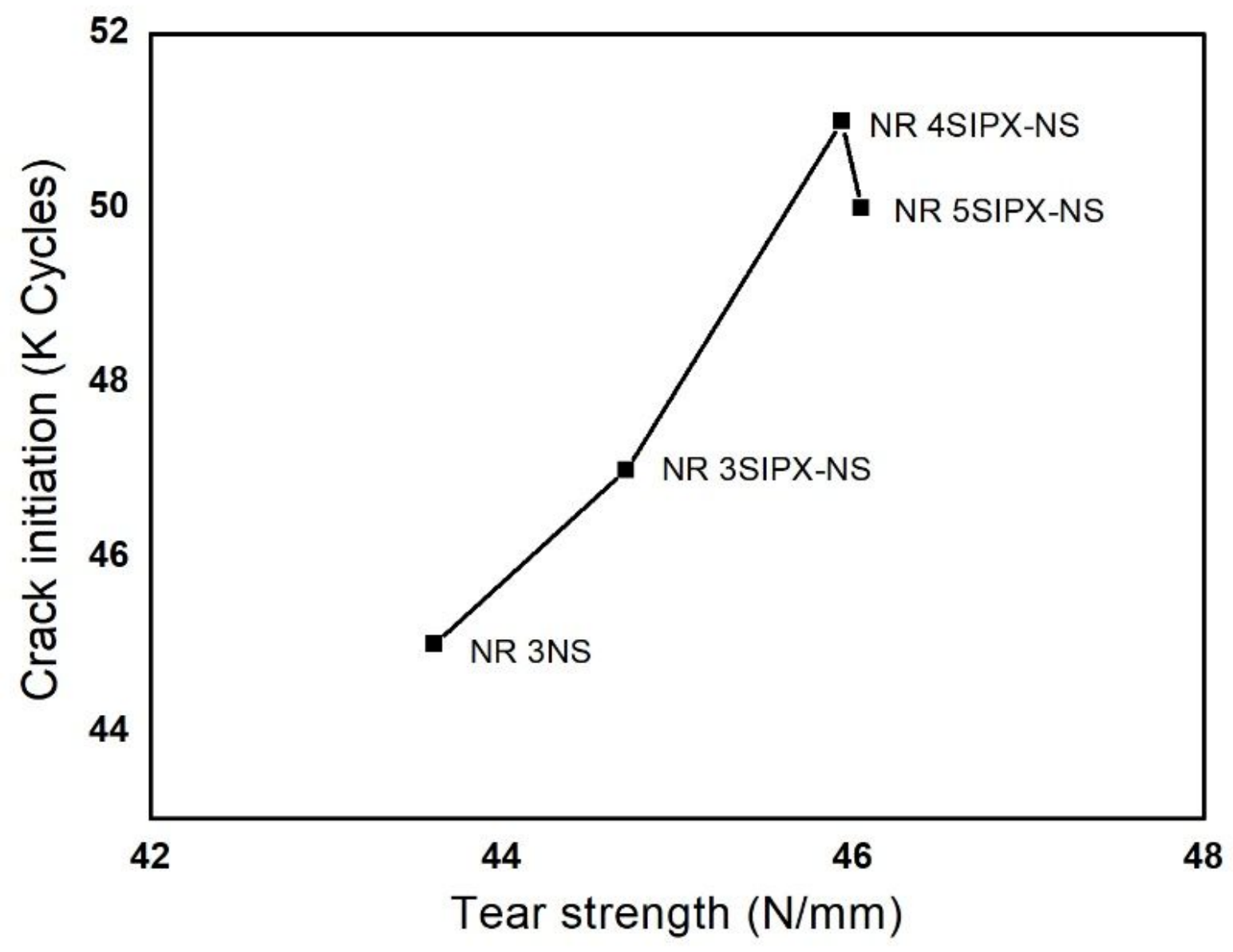

Figure 8

Relationship between tear strength and crack initiation of NR nanocomposites

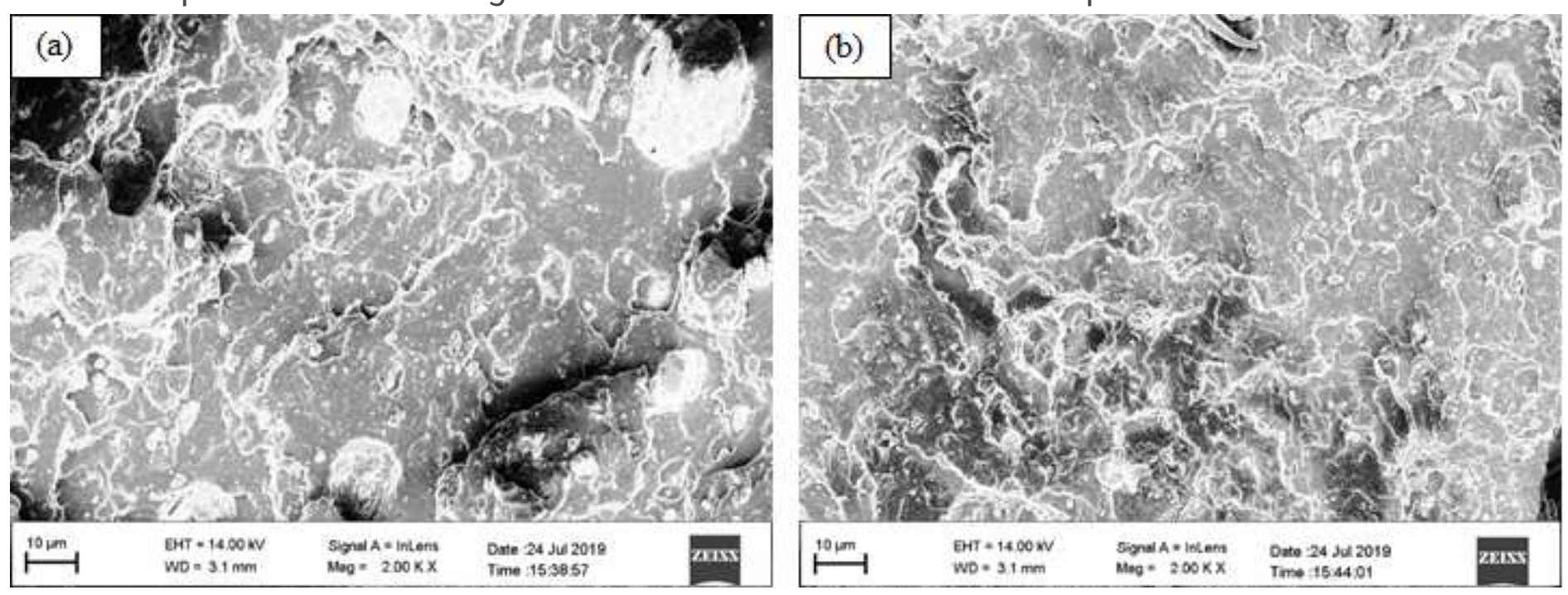

Figure 9 


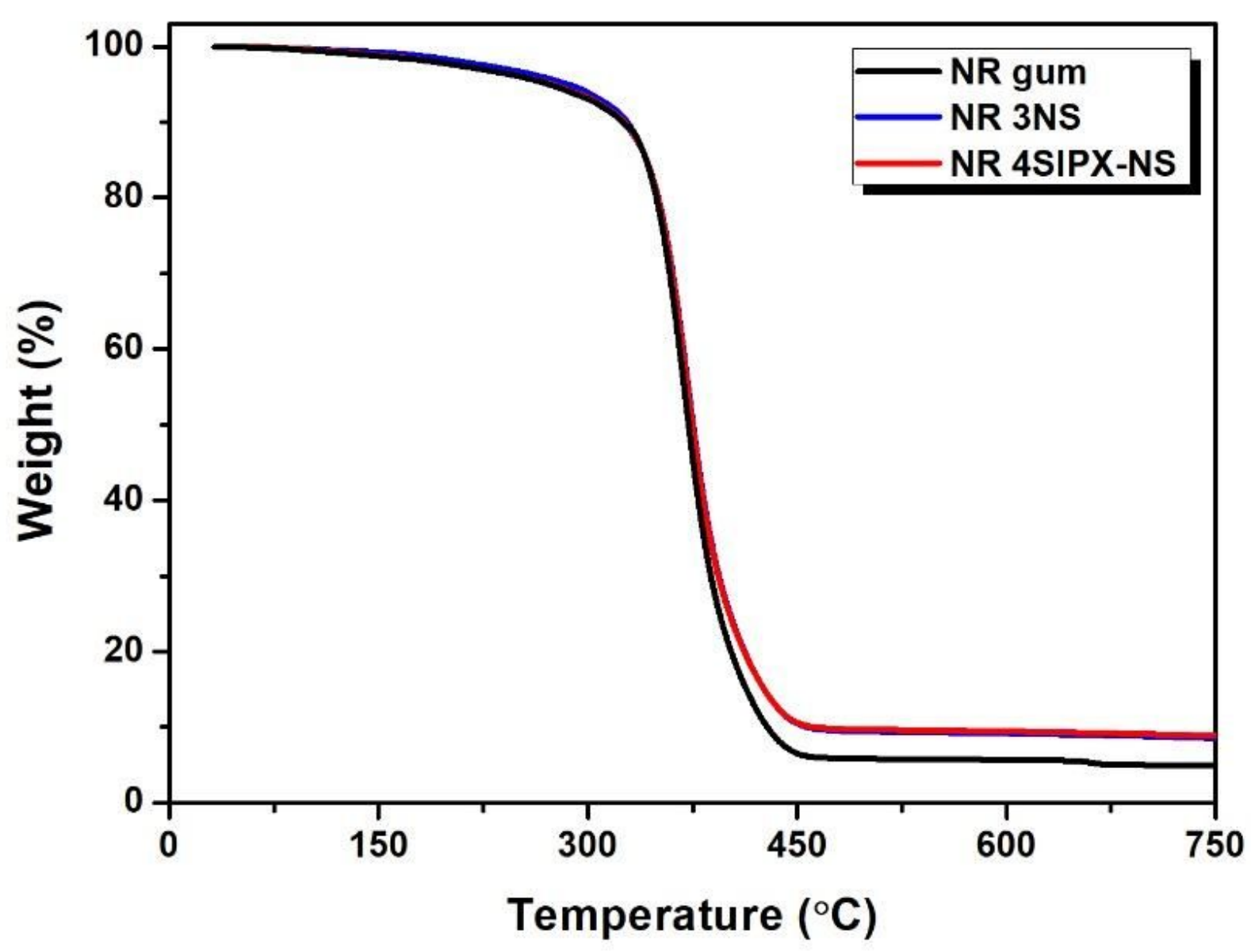

Figure 10

TG analysis of NR 4SIPX-NS, NR 3NS and NR gum

\section{Supplementary Files}

This is a list of supplementary files associated with this preprint. Click to download.

- GraphicalAbstarct.png 